\title{
Identification of QTLs linked to fruit quality traits in apricot (Prunus armeniaca $L$.) and biological validation through gene expression analysis using qPCR
}

\author{
Beatriz Ester García-Gómez • Juan Alfonso Salazar • \\ Luca Dondini • Pedro Martínez-Gómez • David Ruiz
}

\begin{abstract}
Nine important fruit quality traits - including fruit weight, stone weight, fruit diameter, skin ground colour, flesh colour, blush colour, firmness, soluble solids content and acidity content-were studied for two consecutive years in two $\mathrm{F}_{1}$ apricot progeny derived from the crosses 'Bergeron' $\times$ 'Currot' $(B \times C)$ and 'Goldrich' $\times$ 'Currot' $(\mathrm{G} \times \mathrm{C})$. Results showed great segregation variability between populations, which was expected because of the polygenic nature and quantitative inheritance of all the studied traits. In addition, some correlations were observed among the fruit quality traits studied. QTL (quantitative trait loci) analysis was carried out using the phenotypic data and genetic linkages maps of ' $B \times C$ ' and ' $G \times C$ ' obtained with SSR and SNP markers. The most significant QTLs were localised in LG4 for soluble solids content and in LG3 for skin and flesh colour. In LG4, we can highlight the presence of candidate genes involved in D-glucose and D-mannose
\end{abstract}

Beatriz Ester García-Gómez and Juan Alfonso Salazar contributed equally to this work.

Electronic supplementary material The online version of this article (https://doi.org/10.1007/s11032-018-0926-7) contains supplementary material, which is available to authorized users.

B. E. García-Gómez · J. A. Salazar •

P. Martínez-Gómez $(\triangle) \cdot D$. Ruiz

Departamento de Mejora Vegetal, CEBAS-CSIC, PO Box 164, E-30100 Espinardo, Murcia, Spain

e-mail: pmartinez@cebas.csic.es

L. Dondini $(\bowtie)$

Dipartimento di Scienze Agrarie, Università degli Studi di

Bologna, Via Fanin 46, 40127 Bologna, Italy

e-mail: luca.dondini@unibo.it binding, while in LG3, we identified MYB genes previously linked to skin colour by other authors. In order to clearly identify the candidate genes responsible for the analysed traits, we converted the QTLs into expression QTLs and analysed the abundance of transcripts in the segregating genotypes ' $\mathrm{GC} 2-11$ ' and ' $\mathrm{GC} 3-7$ ' from the $\mathrm{G} \times \mathrm{C}$ population. Using $\mathrm{qPCR}$, we analysed the gene expression of nine candidate genes associated with the QTLs identified, including transcription factors $(M Y B$ 10), carotenoid biosynthesis genes ( $L O X 2, C C D 1$ and CCD4), anthocyanin biosynthesis genes (ANS, UFGT and $F 3^{\prime} 5^{\prime} H$ ), organic acid biosynthesis genes (NAD $M E$ ) and ripening date genes $(N A C)$. Results showed variable expression patterns throughout fruit development and between contrasted genotypes, with a correlation between validated genes and linked QTLs. The $M Y B 10$ gene was the best candidate gene for skin colour. In addition, we found that monitoring NAC expression is a good RNA marker for evaluating ripening progression.

Keywords Apricot Prunus armeniaca · Fruit quality . Breeding QTL · Candidate gene · qPCR

\section{Introduction}

Apricot (Prunus armeniaca L.) is one of the most important and desirable of the temperate tree fruits, with a total world production of around 3.88 million tonnes in $2016 \mathrm{http}: / / w w w . f a o . o r g / f a o s t a t / e n / \# d a t a)$. It is the third stone fruit in terms of worldwide economic importance

This is a post-peer-review, pre-copyedit version of an article published in MOLECULAR BREEDING. The final authenticated version is available online at: http://dx.doi.org/10.1007/s11032-018-0926-7. This version is subjected to Springer Nature terms for reuse that can be found at: https://www.springer.com/gp/open-access/authors-rights/aam-terms-v1 
after peach and plum. Fruit quality is a key factor for apricot consumption, and the priorities of apricot breeding programmes are therefore good fruit taste, improved attractiveness and good postharvest behaviour among new varieties (Infante et al. 2011). These features are required for competitiveness in the globalised markets. In addition, demand is increasing for high levels of carotenoids and polyphenols in new varieties, since these compounds have a positive effect on health due to their antioxidant and defensive activity against a variety of degenerative diseases (Hertog et al. 1993; Machlin 1995; Van den Berg et al. 2000; Bazzano et al. 2002).

Fruit quality is a complex human concept including sensory properties (appearance, texture, taste and aroma), nutritional values, chemical compounds, mechanical properties and functional properties (Infante et al. 2008). A high number of pomological traits influence the fruit quality in apricot. In addition, most apricot fruit quality traits - such as soluble solids content, acidity, skin colour, blush colour and firmness - are polygenic and quantitatively inherited (Ruiz and Egea 2008; Ruiz et al. 2008, 2010; Salazar et al. 2013, 2014, 2016). Several QTLs linked to these fruit quality traits have been described in this species (Ruiz et al. 2010; Salazar et al. 2013, 2014).

The final goal of identifying these QTL regions is to convert conventional QTLs into expression QTLs (eQTLs) in order to clearly identify candidate genes responsible for the analysed traits. The eQTLs are genetic regions identified by applying QTL localisation methods to data on the abundance of transcripts in segregating genotypes (Druka et al. 2010). eQTLs are then derived from polymorphisms in the genome that result in differential measurable transcript levels (Salazar et al. 2014), where a correlation between genotype and expression levels is detected (Conesa et al. 2016). These associations can help us unravel the genetic bases of complex traits with a composite of interacting genes, such as colour (Sugiyama et al. 2014; Huang et al. 2014) or seed size (Ye et al. 2014). The biological validation of QTLs through gene expression analysis using qPCR has recently been assayed in Vitis vinifera (Huang et al. 2014), Citrus sp. (Sugiyama et al. 2014), Brassica napus (Lang et al. 2017) and Rubus idaeus (Simpson et al. 2017). To date, however, eQTL studies have not been performed in Prunus species to the best of our knowledge.
This work consists of a 2-year inheritance study of the most important fruit quality traits (fruit weight, stone weight, fruit diameter, fruit skin colour, flesh colour, blush colour, firmness, soluble solids and acidity) in two $F_{1}$ apricot progeny with a common male parent. In addition, the identification of stable QTLs enabled us to assay candidate genes located inside these QTL regions through gene expression analysis using qPCR.

\section{Material and methods}

\section{Germplasm}

The plant material assayed included two $F_{1}$ apricot progeny from the crosses between 'Bergeron' $\times$ 'Currot' $(\mathrm{B} \times \mathrm{C})$ and 'Goldrich' $\times$ 'Currot' $(\mathrm{G} \times \mathrm{C})$ with 187 and 200 seedlings, respectively. The ' $\mathrm{B} \times \mathrm{C}$ ' and ' $\mathrm{G} \times \mathrm{C}$ ' seedlings were planted in field conditions in 2009. 'Bergeron' is a French cultivar characterised by a late ripening time, high fruit weight, an attractive orange fruit colour, medium firmness, medium sugar content and acidity, high carotenoid levels and a good canning and cold storage capacity. 'Goldrich' is a North American cultivar from the cross 'Sunglo' $\times$ 'Perfection' characterised by a medium ripening time, an orange fruit colour, high fruit weight, high firmness, medium sugar content, high acidity and high carotenoid levels. Finally, the common male parent 'Currot' is a traditional Spanish cultivar characterised by a very early ripening time, low fruit weight, a light yellow colour, medium to low firmness, high sugar content, low acidity and low carotenoid levels. In addition, within the ' $\mathrm{G} \times \mathrm{C}$ ' progeny, two genotypes-'GC 2-11' and 'GC 3-7'-were selected for qPCR analysis. These genotypes were selected because they showed similar phenology and fruit characteristics with the exception of the fruit colour. 'GC $2-11$ ' is self-compatible and early blooming and has an intermediate-sized oblong fruit with yellow skin, intense red blush and a yellow flesh colour. 'GC 3-7' is also self-compatible and early blooming with an intermediate-sized oblong fruit but with orange skin, intense red blush and a light orange flesh colour.

\section{Phenotyping protocols}

Several fruit quality traits were analysed for a period of two consecutive years (2012 and 2013). These traits 
included physical traits (fruit weight, stone weight, fruit diameter, fruit colour and firmness) and biochemical traits (soluble solids and acidity). Fifty fruits per genotype were collected at the optimal ripening state, based on their skin ground colour (fully-coloured) and firmness (Sims and Comin 1963), in order to then select 12 fruits per genotype for fruit quality evaluations. Fruit and stone weight were measured using a Blauscal digital scale (model AH-600), with an accuracy of $0.01 \mathrm{~g}$. Fruit skin colour, flesh colour, and blush colour were determined with a Minolta Chroma Meter (CR-300; Minolta, Ramsey, NJ, USA) tri-stimulus colour analyser calibrated to a white porcelain reference plate using a CIELAB scale with colour space coordinates $\mathrm{L}^{*}, \mathrm{a}^{*}$ and $\mathrm{b}^{*}$. To assess colour, we used the Hue angle $\left[\mathrm{H}^{\circ}=\right.$ arctangent $\left.\left(b^{*} / a^{*}\right)\right]$ parameter, which was determined around the equatorial region (Brown and Walker 1990). Firmness was quantified by a compression test in Newtons (N) using a Lloyd press (model LR10K; Fareham, Hants, UK). Soluble solid content (SS) was measured in ${ }^{\circ}$ Brix, calibrated as the percentage of sucrose at $20^{\circ} \mathrm{C}$ using a digital Optic Ivymen System (model DR-101). Finally, acidity was determined using $2 \mathrm{~g}$ of homogenised sample diluted in $30 \mathrm{ml}$ of distilled water, and the values were obtained as grams of malic acid/100 ml, since this is the dominant organic acid in apricots (Souty et al. 1990).

All of the evaluated traits were analysed in 12 fruits per genotype and year. As for acidity and soluble solids, we evaluated these traits in three replicates resulting from the pool of 12 fruits. We used SPSS 12.0 software for Windows (Chicago, USA) to perform the statistical analyses. Frequency histograms were constructed for each fruit quality trait using the average value of each seedling in two different years. ANOVA analysis was performed to highlight differences among genotypes and years for those traits that met the criteria of normality according to Shapiro-Wilk, while the traits that did not meet the criteria of normality were analysed by the Kruskal-Wallis non-parametric test. Bivariate correlations between different traits were calculated with row data from the 2 years using the Pearson correlation coefficient.

In addition, samples were collected for qPCR analysis during the fruit development and ripening periods at three different times: A, at the beginning of veraison; B, during colour change and advanced veraison; and $\mathrm{C}$, when the fruit was mature and showed its full colour state.
Marker identification and analysis

The new SSR and SNP markers assayed were located in scaffolds 3 and 4 of the Prunus reference genome v1.0 (http://www.rosaceae.org/peach/genome; Verde et al. 2013), where different QTLs linked to fruit quality traits have been described in peach (Eduardo et al. 2011; Fresnedo-Ramírez et al. 2015), apricot (Salazar et al. 2014) and Japanese plum (Salazar et al. 2017). These markers were identified by mapping the transcriptome reads obtained by NGS reads in BAM format, available after an RNA-Seq approach on five different cDNA libraries from 'Rojo Pasión', two from 'Z506-7' (Salazar et al. 2015) and two different cDNA libraries from 'Bergeron' $\times$ 'Currot'. The reads were processed by SAMtools ( $\mathrm{Li}$ et al. 2009) and displayed in alignment with the peach genome by Tablet (Milne et al. 2013) with the Prunus reference genome. The sequences were uploaded to the Phytozome website, and mask options were used to identify and eliminate repetitive domains. Total genomic DNA was extracted from young expanded leaves using the CTAB procedure described by Doyle and Doyle (1987).

For mapping, 25 new SNPs were selected and organised using 1 SNPlex, and 16 new SSRs were analysed by multiplex. SSR amplifications were performed according to multiplex PCR protocol as described by Campoy et al. (2010), using tag F primer labelled with FAM, TAM or HEX fluorescent dyes and unlabelled tag R primer. A volume of $3 \mu$ of genomic DNA (concentration $10 \mathrm{ng} / \mu \mathrm{l}$ ) was used in a $10-\mu \mathrm{l}$ reaction mix. For fragment analysis, $3 \mu \mathrm{l}$ of each PCR was mixed with $7 \mathrm{ml}$ of formamide and $0.2 \mu \mathrm{l}$ of GeneScan 500 LIZ® standard and sequenced using an ABI Prism 3730 DNA Analyser (Applied Biosystems, MA, USA). SSR peaks were visualised using Peak Scanner 1.0 software. The SNP design and analysis was performed according to Salazar et al. (2015). One independent SNPlex array was designed using MassARRAY Assay Design 3.1 software (available for the Sequenom platforms) in which the 25 selected SNPs were included.

Linkage analysis and QTL identification

Genetic linkage maps were constructed by JoinMap.3 (Van Ooijen 2006), and QTL identification was carried out using MapQTL ver. 4. Linkage groups 3 and 4 were reconstructed using the Kosambi function with a 
frequency of recombination of 0.4 and a minimum LOD value over 3. As for QTL identification, phenotypic and genotypic data were analysed by first performing a test of 1000 permutations to designate the LOD threshold reference of $\alpha<0.05, \alpha<0.01$ and $\alpha<0.001$ (genomewide) for each fruit quality trait using QTL detection interval mapping (parametric test) and the Kruskal-Wallis test (non-parametric test). In addition, the strongest marker cofactors of each QTL were identified by 'Automatic Cofactor Selection', and Multiple QTL analysis was applied in order to identify the most significant markers of the QTL interval. Linkage maps and QTL intervals were drawn using MapChart 2.3 software (Voorrips 2002) and the LOD colour gradient by Harry Plotter (Java software).

Biological validation of eQTLs through gene expression analysis using qPCR

Total RNA was extracted from the fruit mesocarps using a modified PowerPlant ${ }^{\circledR}$ RNA Isolation Kit (www. mobio.com), including a treatment with DNAse I during extraction with an On-Spin Column DNAse I Kit® (www.mobio.es). The cDNA was synthetised using SuperScript III Reverse Transcriptase (Thermo Fisher Scientific). To investigate the expression pattern, we evaluated nine candidate genes associated with the identified QTLs using qPCR, including transcription factors (MYB 10), carotenoid biosynthesis genes ( $L O X$ 2, CCD1 and CCD4), anthocyanin biosynthesis genes (ANS, UFGT and F3'5' H), organic acid biosynthesis genes (NAD ME) and ripening date genes $(N A C)$. Real-time qPCR experiments were performed with a StepOnePlus Real-Time PCR System (Applied Biosystems). Specific primers were designed based on previously obtained sequences in apricot libraries using Primer3 software (Supplementary Table 1) or validated using primers designed and assayed in peach.

We evaluated qPCR efficiency using the standard curve method. For all real-time qPCR reactions, we made a 10 - $\mu$ l mix including $5 \mu$ l Power SYBR $®$ Green PCR Master Mix (Applied Biosystems), $0.5 \mu$ of each primer $(5 \mu \mathrm{M})$ and $2 \mu \mathrm{l}$ of $\operatorname{cDNA}(2.5 \mathrm{ng} / \mu \mathrm{l})$. Each sample was analysed in triplicate from a pool of fruits collected in 2017. S18, RPL12 and CYP1 were analysed as candidate housekeeping genes using the RefFinder web tool (Xie et al. 2012) (http://leonxie. esy.es/RefFinder/?type=reference). R version 3.4.2 with default setting was used to perform the statistical analyses of differential gene expression (RStudio 2015). Frequency histograms were constructed for each gene using the average value of each genotype and ripening state. Before checking the normality, homocestadicity and sample independence. We used the Kruskal-Wallis rank sum test (Hollander et al. 2013) for non-parametric distributions to determine the differences between the medians.

\section{Results}

Descriptive phenotypic analysis

The phenotypical characterisation was focused on phenotyping the plant material and studying the inheritance of the most important fruit quality traits in the apricot progeny 'Bergeron' $\times$ 'Currot' ('B $\times \mathrm{C}$ ') and 'Goldrich' $\times$ 'Currot' (' $\mathrm{G} \times \mathrm{C}$ '). We did this by assaying 187 and 200 seedlings, respectively (Fig. 1 and Supplementary Table 2). In both progeny, there were significant differences by genotype and year for all evaluated traits (Supplementary Tables 3 and 4). Different frequency histograms were also constructed using the average data for each seedling, trait and year, which revealed normal distribution among the majority of traits studied in both progeny (Fig. 1). The Shapiro-Wilk normality test corroborated this normality (Supplementary Table 5). We can therefore confirm the polygenic nature and quantitative inheritance of all the traits studied.

A low fruit diameter influence was observed in both ' $\mathrm{B} \times \mathrm{C}$ ' and ' $\mathrm{G} \times \mathrm{C}$ ' populations, which may be due to the small size of 'Currot'. Furthermore, the fruit skin colour of the seedlings was closer to that of 'Currot' (the parent in both populations). Intermediate inheritance with respect to parents was especially observed in seedlings in terms of acidity level ( $\mathrm{g}$ malic acid/100 $\mathrm{ml}$ ) in the ' $\mathrm{G} \times \mathrm{C}$ ' population, which may be due to high acidity from 'Goldrich' (2.6-3 g/100 ml) and low acidity from 'Currot' (1-1.4 g/100 ml). By contrast, for soluble solid content, we found transgressive values both above and below those observed in the parents $\left(7-18^{\circ} \mathrm{Brix}\right)$ in both progeny (Fig. 1).

Finally, according to the Pearson correlation analysis, we were able to confirm a high correlation between years for all evaluated traits, especially for fruit skin colour $\left(0.670^{* *}\right)$, flesh colour $\left(0.738^{* *}\right)$, acidity $(0.764 * *)$ and soluble solids $(0.720 * *)$. Results show 

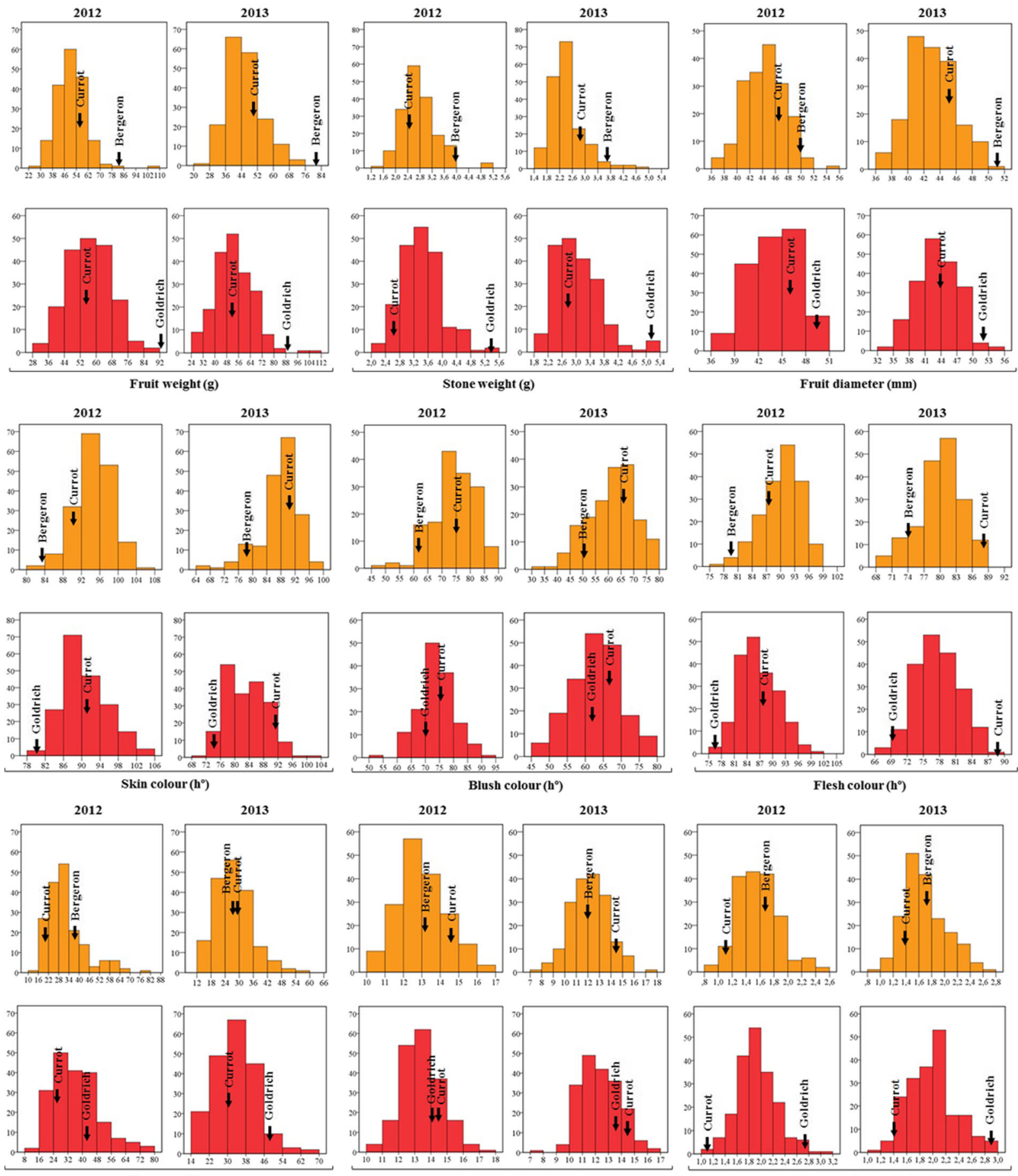

Firmness (N)

Soluble solids ( $\left.{ }^{\circ} \mathrm{Brix}\right)$

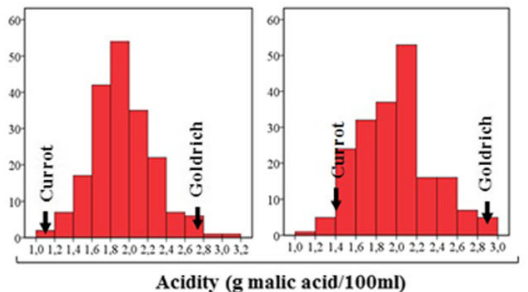

Fig. 1 Distribution among 187 seedlings of 'Bergeron' $\times$ 'Currot' (orange bars) and 200 seedlings of 'Goldrich' $\times$ 'Currot' (red bars) $\mathrm{F}_{1}$ apricot progeny of the following fruit quality traits: ripening

that these traits are quite balanced between years. We also found correlations among different traits that date, fruit weight, stone weight, fruit diameter, skin colour, blush colour, flesh colour, firmness, soluble solids and acidity for the years 2012 and 2013

occurred every year, such as correlations between skin and flesh colour $\left(0.808^{* *}\right)$ and a low correlation 
between acidity and fruit skin colour $(-0.238 * *)$ (Table 1).

Marker-trait analyses

New genetic markers were added to the genetic maps of two $F_{1}$ apricot progeny derived from the cross 'Bergeron' $\times$ 'Currot' ('B $\times \mathrm{C}$ ') and 'Goldrich' $\times$ 'Curr ('G×C') previously reported by Salazar et al. (2016). All of these markers were designed with the aim to saturate the LG3 and LG4 of both progeny, where important phenology and fruit quality QTLs were found after preliminary analyses. Thus, a total of new 53 molecular markers (SSRs and SNPs) were mapped in LG3 and LG4 of the ' $\mathrm{B} \times \mathrm{C}$ ' population, while 67 markers (SSRs and SNPs) were mapped in the same LGs for the ' $\mathrm{G} \times \mathrm{C}$ ' population. Finally, increased mapping coverage was obtained for the ' $\mathrm{B} \times \mathrm{C}$ ' $(841.4 \mathrm{cM})$ and ' $\mathrm{G} \times \mathrm{C}$ ' $(789.5 \mathrm{cM})$ populations with respect to the $809.2 \mathrm{cM}$ and $775.8 \mathrm{cM}$ previously reported (Supplementary Table 6). These new molecular markers allow us to saturate the relevant genomic regions in LG3 and LG4, and some of them are potential markers for marker-assisted selection (MAS). In addition, integrated linkage groups for both parents and populations were generated for LG3 and LG4 to obtain more saturated genomic regions for potential phenology and fruit quality QTLs.

Moreover, in the integrated analysis of genotypic and phenotypic data, we identified several QTLs for each quality trait in both progeny (Supplementary Fig. 1 and Fig. 2; Table 2). These QTL results corroborate the great variability and polygenic nature of each pomological trait including different genome regions associated with morphological quantitative traits (fruit weight, stone weight and fruit diameter), morphological qualitative traits (skin colour, blush colour and flesh colour) and organoleptic traits (flesh firmness, soluble solids and acidity).

\section{Morphological quantitative traits (stone and fruit weight and diameter)}

We observed different QTLs linked to fruit (FW) and stone (SW) weight traits in LGs 1, 2, 3, 5, 6 and 7 in both the ' $\mathrm{B} \times \mathrm{C}$ ' and ' $\mathrm{G} \times \mathrm{C}$ ' populations (Supplementary Fig. 1 and Fig. 2). In ' $\mathrm{G} \times \mathrm{C}$ ' progeny, however, the most significant QTLs for FW, SW and fruit diameter (CAL) were located in LG1, which indicates that all of these traits are highly related, while in ' $\mathrm{B} \times \mathrm{C}$ ' progeny, the stone weight QTL was linked to LG6 (Table 2). The LG6 of 'Bergeron' thus seems to be highly related to SW for both years, especially in the middle region chromosome close to the S6_12174633 and __22539524 markers, reaching a percentage of riance explanation (PEV) value of around $20 \%$. Concerning the ' $\mathrm{G} \times \mathrm{C}$ ' progeny, the most important QTLs for SW were on LG1 and LG2, for FW on LG1 and for CAL on LG1 and LG3 with a PEV value above $20 \%$. The most significant marker in ' $\mathrm{G} \times \mathrm{C}$ ' progeny for these traits was S1_38382339 in LG1, which reached LOD values of 7.41 and 9.48 for FW and CAL, respectively, with a PEV value close to $30 \%$. As for the SW QTL, a PEV value close to $40 \%$ was reached for the S1_38382339 marker in 'Goldrich', and another SW QTL was located in LG2 around S2_18992724 with a PEV value close to $20 \%$, coinciding with 'Currot' in the ' $\mathrm{B} \times \mathrm{C}$ ' population. In 'Currot', almost no QTLs were detected for these traits, particularly in ' $\mathrm{B} \times \mathrm{C}$ ' progeny.

\section{Morphological qualitative traits (skin, flesh and blush colour)}

Different skin (SKC), flesh (FLSC) and blush colour (BLSC) QTLs were located along linkage groups 1, 2, 3, 5 and 6 in both ' $\mathrm{B} \times \mathrm{C}$ ' and $\mathrm{G} \times \mathrm{C}$ ' populations (Supplementary Fig. 1 and Fig. 2). The most significant QTLs for the ' $\mathrm{B} \times \mathrm{C}$ ' population were located in LG1 for BLSC and in LG6 for FLSC (Table 2). For the ' $\mathrm{G} \times \mathrm{C}$ ' population, however, the most significant QTLs linked to fruit colour were identified in LG3 for SKC and FLSC (Table 2). In 'Bergeron', a QTL for BLSC was located in LG1 around the S1_14071595 and S1_20067081 markers, reaching a LOD value of around 7 and a PEV of around $30 \%$.

As for the ' $\mathrm{G} \times \mathrm{C}$ ' population, as mentioned above, the most important SKC QTLs were located in LG3 of 'Goldrich', and S3_18629805 and S3_18842927 were the most significant markers with $\mathrm{LOD}_{\overline{\mathrm{D}}}$ values over 20 and a PEV value close to $50 \%$. The same SNPs were also associated with red blush colour and FLSC but with lower LOD values (Supplementary Fig. 2 and Table 2). In Fig. 2, we can see the great influence SKC has at the end of LG3, especially in ' $\mathrm{G} \times \mathrm{C}$ ' progeny. 
Table 1 Pearson correlation coefficients for different fruit quality traits for the years 2012 and 2013 in 187 apricot seedlings of 'Bergeron' $\times$ 'Currot' and 200 apricot seedlings 'Goldrich' $\times$ 'Currot' populations

\begin{tabular}{|c|c|c|c|c|c|c|c|c|c|}
\hline & \multicolumn{9}{|c|}{ 'Bergeron' $\times$ 'Currot' } \\
\hline & FW & SW & CAL & $\mathrm{SKC}$ & BLSC & FLSC & FIRM & SS & MALIC \\
\hline Fruit weight (FW) & $0.498^{* *}$ & $0.644^{* *}$ & $0.915^{* *}$ & -0.044 & -0.004 & 0.008 & $0.280^{* *}$ & 0.000 & -0.101 \\
\hline Stone weight (SW) & $0.573^{* *}$ & $0.772^{* *}$ & $0.515^{* *}$ & $-0.260^{* *}$ & -0.066 & $-0.316^{* *}$ & $0.387^{* *}$ & -0.101 & -0.073 \\
\hline Fruit diameter (CAL) & $0.905^{* *}$ & $0.437^{* *}$ & $0.491^{* *}$ & $0.297^{* *}$ & $0.216^{* *}$ & $0.391^{* *}$ & $-0.172^{*}$ & $-0.168^{*}$ & $-0.254^{* *}$ \\
\hline Skin colour (SKC) & 0.123 & -0.061 & 0.060 & $0.660^{* *}$ & $0.505^{* *}$ & $0.645^{* *}$ & $-0.343^{* *}$ & -0.051 & 0.052 \\
\hline Blush colour (BLSC) & $0.183^{*}$ & 0.136 & 0.083 & $0.390^{* *}$ & $0.424^{* *}$ & $0.308^{* *}$ & $-0.227^{* *}$ & $-0.253^{* *}$ & $-0.179^{*}$ \\
\hline Flesh colour (FLSC) & $0.208^{* *}$ & -0.070 & 0.143 & $0.722^{* *}$ & $0.270^{* *}$ & $0.738^{* *}$ & $-0.259^{* *}$ & -0.014 & -0.038 \\
\hline Firmness (FIRM) & 0.023 & $0.363^{* *}$ & $0.176^{*}$ & $-0.201^{* *}$ & -0.002 & $-0.179^{*}$ & $0.638^{* *}$ & -0.114 & $0.156^{*}$ \\
\hline Soluble solids (SS) & $-0.220^{* *}$ & $-0.268^{* *}$ & -0.009 & -0.098 & $-0.241^{* *}$ & $-0.164^{*}$ & 0.056 & $0.720^{* *}$ & $0.197^{* *}$ \\
\hline \multirow[t]{3}{*}{ Acidity (MALIC) } & $-0.235^{* *}$ & 0.023 & -0.143 & $-0.238^{* *}$ & -0.065 & $-0.165^{*}$ & -0.076 & $0.434^{* *}$ & $0.687^{* *}$ \\
\hline & \multicolumn{9}{|c|}{ 'Goldrich' × 'Currot' } \\
\hline & FW & SW & CAL & $\mathrm{SKC}$ & BLSC & FLSC & FIRM & SS & MALIC \\
\hline Fruit weight (FW) & $0.515^{* *}$ & $0.757^{* *}$ & $0.952^{* *}$ & -0.002 & 0.093 & 0.040 & $0.328^{* *}$ & 0.082 & -0.002 \\
\hline Stone weight (SW) & $0.735^{* *}$ & $0.452^{* *}$ & $0.663^{* *}$ & -0.060 & 0.085 & -0.062 & $0.435^{* *}$ & 0.082 & $0.206^{* *}$ \\
\hline Fruit diameter (CAL) & $0.932^{* *}$ & $0.628^{* *}$ & $0.542^{* *}$ & $0.208^{* *}$ & $0.175^{*}$ & $0.246^{* *}$ & 0.087 & $-0.200^{* *}$ & $-0.145^{*}$ \\
\hline Skin colour (SKC) & 0.118 & -0.134 & 0.046 & $0.670^{* *}$ & $0.550^{* *}$ & $0.786^{* *}$ & $-0.262^{* *}$ & 0.012 & -0.007 \\
\hline Blush colour (BLSC) & 0.088 & -0.112 & 0.128 & $0.542^{* *}$ & $0.371^{* *}$ & $0.378^{* *}$ & -0.052 & -0.097 & -0.032 \\
\hline Flesh colour (FLSC) & $0.162^{*}$ & -0.102 & 0.121 & $0.808^{* *}$ & $0.374^{* *}$ & $0.733^{* *}$ & -0.139 & 0.074 & -0.044 \\
\hline Firmness (FIRM) & $0.142^{*}$ & $0.285^{* *}$ & $0.278^{* *}$ & $-0.232^{* *}$ & $-0.225^{* *}$ & $-0.179^{*}$ & $0.583^{* * *}$ & -0.061 & $0.213^{* *}$ \\
\hline Soluble solids (SS) & $-0.205^{* *}$ & $-0.181^{*}$ & 0.069 & -0.051 & $-0.176^{*}$ & -0.041 & $0.287^{* *}$ & $0.603^{* *}$ & $0.182^{*}$ \\
\hline Acidity (MALIC) & -0.119 & 0.055 & -0.066 & -0.101 & -0.022 & -0.063 & $0.218^{* *}$ & $0.276^{* *}$ & $0.764^{* * *}$ \\
\hline
\end{tabular}

The correlation is significant at the $0.05\left(^{*}\right)$ and 0.01 levels $(* *)$. The diagonal italicized line shows the correlation between years. Below the diagonal line, the results correspond to the 2012 correlation while those above the line show the correlation for 2013

\section{Organoleptic traits}

Regarding fruit firmness in the ' $\mathrm{B} \times \mathrm{C}$ ' population, we only found linked QTLs in LG4, reaching a LOD value of 11.27 and a PEV value of 35\% (Supplementary Fig. 1 and Table 2). This QTL is located in the middle region of chromosome 4 close to S4_10035210, S4_13001709 and SSR4_13182815 (Table 2). In the ' $\mathrm{G} \times \mathrm{C}$ ' population, however, fruit firmness QTLs were detected in LGs 1, 2, 3, 4, and 6 (Supplementary Fig. 2). In 'Goldrich', the most important QTL was identified in LG 6, showing a PEV above 30\% for the marker S6_5217065. As for the 'Currot' parent, LGs 2 and 3 seem to be strongly related to firmness, and S2_12550486, SSR3_15343739 and S3_15588939 are the most significant markers with a PEV value of around $20 \%$ (Table 2). In ' $\mathrm{G} \times \mathrm{C}$ ' progeny, especially for LG1 and LG3, firmness and reddish skin colour may be inherited together from 'Goldrich', which is characterised by a high level of firmness and an intense fruit skin colour.

Sugar content is a relevant trait for fruit quality and together with acidity contributes to the fruit taste, influencing consumer perceptions. QTLs for soluble solid (SS) content were identified along LGs 2, 3 and 4 (Supplementary Fig. 1 and Fig. 2), although the most significant QTLs were identified in LG4 for both populations. In ' $\mathrm{B} \times \mathrm{C}$ ' and ' $\mathrm{G} \times \mathrm{C}$ ' progeny, SS QTLs were consistent for both years, and S4_10035210, UDAp439, SSR4_13182815 and S4_13642265 (Fig. 2) were the most important markers.

QTL intervals in the other LGs reached lesser significance values than in LG4 for both populations. In the integrated LG4, in the QTL region for soluble solids, markers of both parents are included. The results show a greater influence downstream of SSR UDAp439, highlighting the QTL interval between S4_9061773 


\section{Skin color}
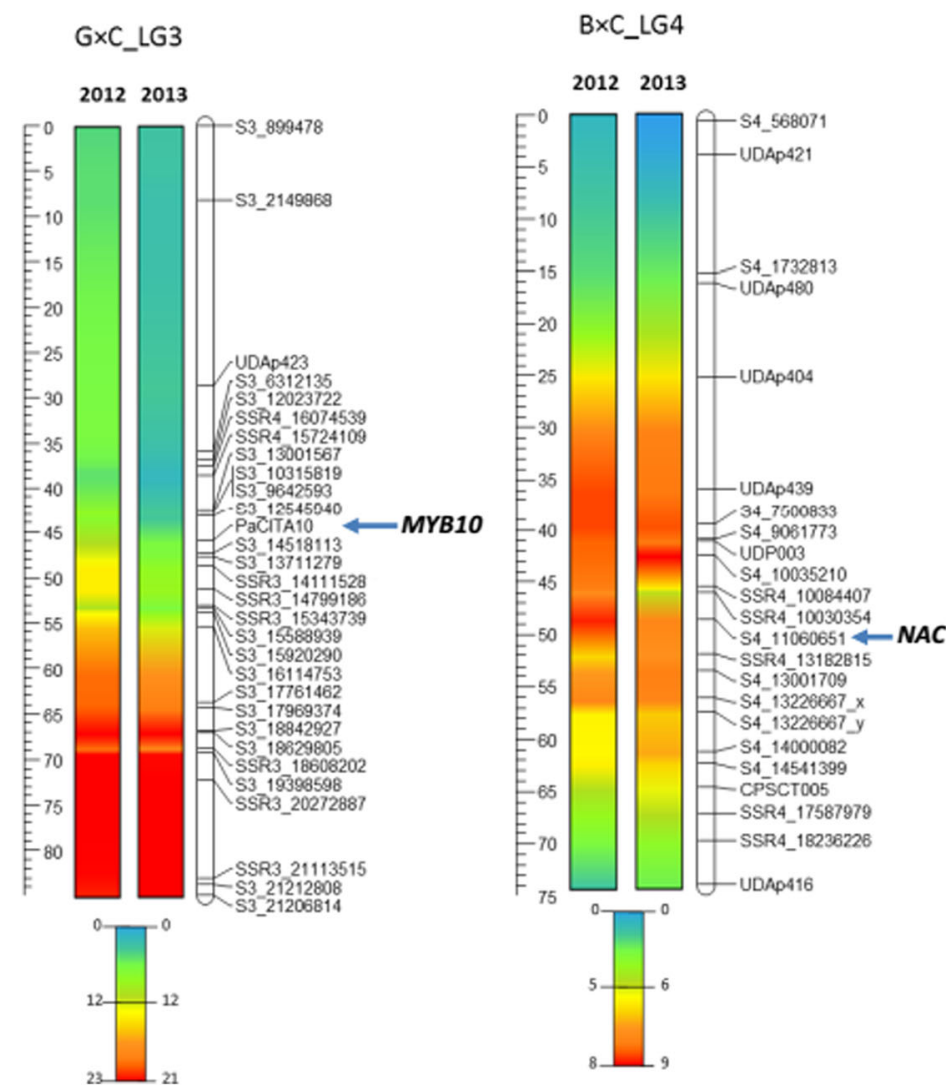

G×C_LG4

20122013

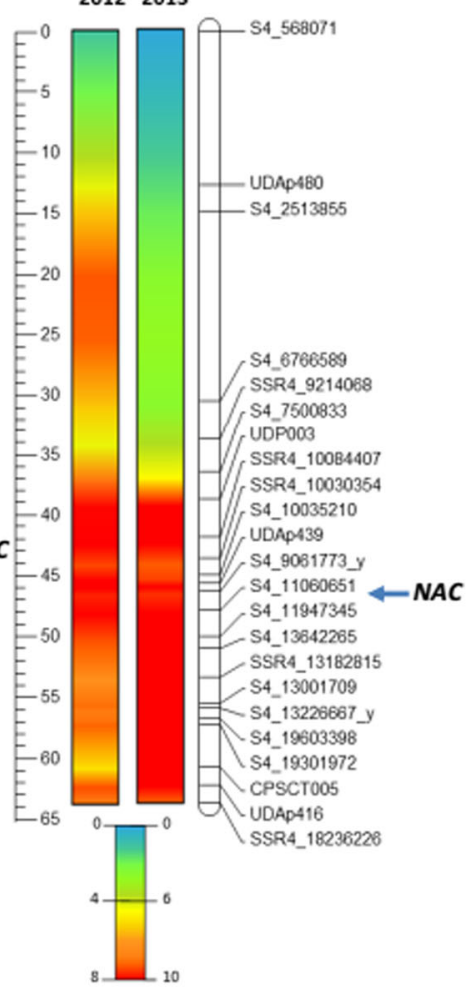

Fig. 2 LOD gradient scores by interval mapping analysis for skin colour in ' $\mathrm{G} \times \mathrm{C}$ ' in $\mathrm{LG} 3$ and soluble solids in both the ' $\mathrm{B} \times \mathrm{C}$ ' and ' $\mathrm{G} \times \mathrm{C}$ ' populations in LG4. On the left side of each chromosome,

and S4_11947345 (Fig. 2). LG4 undoubtedly has the greatest influence on this trait.

Acidity (the malic acid concentration) also plays an important role in fruit quality and flavour. In ' $\mathrm{B} \times \mathrm{C}$ ' progeny, different acidity QTLs were identified in LGs 1 and 8 (Supplementary Fig. 1). The most important QTLs, however, were located at the beginning of LG8 in 'Bergeron' (in a region close to the marker S8_13630387), reaching a PEV value above $30 \%$ for both years. In the LG8 of 'Currot', on the other hand, the nearest marker linked to acidity was S8_4773161, reaching a PEV value close to $60 \%$ (Table 2 ). In the ' $\mathrm{G} \times \mathrm{C}$ ' population, different QTLs were localised in LGs 2, 5, 6 and 8 (Supplementary Fig. 2), and the most significant QTLs were those obtained in LG2 and LG8 of 'Goldrich' and 'Currot', respectively. In 'Goldrich', in LG2, the markers S2_18992724 and UDAp456 reached significant LOD values of around the centimorgan (cM) scale is shown, and below each chromosome, the LOD range is shown by colour gradient. The assayed candidate genes are indicated with arrows in bold and italics

7 and a PEV value of 20\% (Etienne et al. 2002a; Xi et al. 2016).

As for LG8, QTLs for both years were located at the end of the LG in 'Currot', involving the markers S8_17732612 and UDP98409 (Supplementary Fig. 1 and Fig. 2). This QTL interval reached a LOD value of around 7 and a PEV value above $20 \%$ (Table 2). In the 'Goldrich' parent, the nearest marker linked to acidity was S8_15339816, reaching a PEV value of over $20 \%$. The QTLs linked to acidity were thus consistent for both populations and years, especially in LG8, so it would be interesting to explore this chromosome more in depth in conjunction with this trait.

Candidate genes and biological validation

The results of qPCR analysis show that $S 18, R P L 12$ and CYP1 are the best housekeeping genes. S18 was 
Table 2 Summary of the most significant markers linked to QTLs of fruit quality traits [ripening time (RT), stone weight (SW), firmness (FIRM), blush colour (BLSC), soluble solids (SS) and acidity (MALIC)] by interval mapping (IM) and multiple QTL mapping (MQM) in a F1 apricot progeny of 'Bergeron' $\times$ 'Currot' and 'Goldrich' $\times$ 'Currot' during the years 2012 ( 12$)$ and 2013 (13). LOD threshold for QTL intervals: ** $\alpha<0.05$, *** $\alpha<0.01$

\begin{tabular}{|c|c|c|c|c|c|c|}
\hline \multicolumn{7}{|l|}{ 'Bergeron' } \\
\hline Trait-Year & LG & QTL interval (IM) & Location & Nearest marker (MQM) & lod & $\% \operatorname{expl}$ \\
\hline SW_12 & 6 & {$[36.7 ; 52.8]^{* *}$} & 41.1 & S6_22539524 & 5.47 & 21.2 \\
\hline FLSC_12 & 6 & {$[41.1 ; 52.8]^{* *}$} & 41.1 & S6_22539524 & 4.77 & 20.7 \\
\hline FIRM_12 & 4 & {$[33.6 ; 56.3]^{* * *}$} & 46.0 & S4_13001709 & 6.56 & 21.2 \\
\hline SS_12 & 4 & {$[32.3 ; 42.7]^{* * *}$} & 38.7 & S4_10035210 & 7.75 & 26.2 \\
\hline MALIC_12 & 8 & {$[0.0 ; 10.1]^{* *}$} & 0.0 & S8_13630387 & 3.47 & 33.2 \\
\hline SW_13 & 6 & {$[10.0 ; 21.7]^{* *}$} & 21.7 & S6_12174633 & 5.14 & 22.9 \\
\hline SW_13 & 6 & {$[36.7 ; 41.1]^{* *}$} & 41.1 & S6_22539524 & 5.61 & 20.8 \\
\hline BLSC_13 & 1 & {$[39.9 ; 46.5]^{* * *}$} & 43.2 & S1_14071595 & 7.09 & 29.0 \\
\hline BLSC_13 & 1 & {$[39.0 ; 46.5]^{* * *}$} & 44.0 & S1_20067081 & 7.34 & 30.9 \\
\hline FIRM_13 & 4 & {$[33.6 ; 56.3]^{* * *}$} & 38.7 & S4_10035210 & 11.27 & 35.0 \\
\hline FIRM_13 & 4 & {$[33.6 ; 56.3]^{* * *}$} & 44.7 & SSR4_13182815 & 7.92 & 24.5 \\
\hline SS_13 & 4 & {$[33.6 ; 56.3]^{* * *}$} & 38.7 & S4_10035210 & 9.4 & 29.6 \\
\hline SS_13 & 4 & {$[33.6 ; 56.3]^{* * *}$} & 44.7 & SSR4_13182815 & 7.17 & 22.6 \\
\hline MALIC_13 & 8 & {$[0.0 ; 10.1]^{* *}$} & 0.0 & S8_13630387 & 4.71 & 45.8 \\
\hline \multicolumn{7}{|l|}{ 'Goldrich' } \\
\hline SKC_12 & 3 & {$[15.4 ; 43.7]^{* * *}$} & 37.8 & S3_17969374 & 19.23 & 42.5 \\
\hline SKC_12 & 3 & {$[15.4 ; 43.7]^{* * *}$} & 40.4 & S3_18842927 & 22.98 & 50.0 \\
\hline FLSC_12 & 3 & {$[15.4 ; 43.7]^{* * *}$} & 37.8 & S3_17969374 & 17.3 & 38.9 \\
\hline FLSC_12 & 3 & {$[15.4 ; 43.7]^{* * *}$} & 40.4 & S3_18842927 & 18.79 & 43.2 \\
\hline FIRM_12 & 6 & {$[0.9 ; 9.6]^{* *}$} & 4.6 & S6_5217065 & 5.23 & 33.5 \\
\hline FW_13 & 1 & {$[50.4 ; 64.9]^{* *}$} & 64.9 & S1_38382339 & 7.41 & 28.8 \\
\hline SW_13 & 1 & {$[50.4 ; 64.9]^{*}$} & 64.9 & S1_38382339 & 5.38 & 38.7 \\
\hline CAL_13 & 1 & {$[35.4 ; 64.9]^{* *}$} & 64.9 & S1_38382339 & 9.48 & 29.4 \\
\hline SW_13 & 2 & {$[25.9 ; 35.3]^{* *}$} & 35.3 & S2_18992724 & 8.7 & 21.9 \\
\hline SKC_13 & 3 & {$[27.3 ; 43.7]^{* * *}$} & 40.4 & S3_18842927 & 21.95 & 47.0 \\
\hline SKC_13 & 3 & {$[27.3 ; 43.7]^{* * *}$} & 40.6 & S3_18629805 & 21.97 & 47.0 \\
\hline FLSC_13 & 1 & {$[50.4 ; 64.9]^{* *}$} & 64.9 & S1_38382339 & 5.97 & 49.0 \\
\hline FLSC_13 & 3 & {$[27.3 ; 43.7]^{* * *}$} & 40.4 & S3_18842927 & 14.56 & 34.5 \\
\hline FLSC_13 & 3 & {$[27.3 ; 43.7]^{* * *}$} & 40.6 & S3_18629805 & 14.57 & 34.5 \\
\hline SS_13 & 4 & {$[26.6 ; 49.5]^{* * *}$} & 38.6 & S4_13642265 & 10.56 & 27.8 \\
\hline SS_13 & 4 & {$[26.6 ; 49.5]^{* * *}$} & 40.2 & SSR4_13182815 & 10.18 & 25.1 \\
\hline MALIC_13 & 2 & {$[25.9 ; 35.3]^{* *}$} & 33.7 & UDAp456 & 7.15 & 21.5 \\
\hline MALIC_13 & 2 & {$[25.9 ; 35.3]^{* *}$} & 35.3 & S2_18992724 & 7.5 & 20.6 \\
\hline MALIC_13 & 8 & {$[17.0 ; 26.0]^{* *}$} & 21.0 & S8_15339816 & 5.34 & 22.4 \\
\hline \multicolumn{7}{|c|}{ 'Currot' (from the BxC Map) } \\
\hline FIRM_12 & 4 & {$[25.8 ; 64.8]^{* *}$} & 47.5 & S4_13001709 & 6.55 & 21.2 \\
\hline FIRM_12 & 4 & {$[25.8 ; 64.8]^{* *}$} & 47.9 & SSR4_13182815 & 6.49 & 21.0 \\
\hline SS_12 & 4 & {$[25.8 ; 45.2]^{* * *}$} & 38.8 & S4_10035210 & 6.91 & 23.4 \\
\hline SS_12 & 4 & {$[25.8 ; 45.2]^{* * *}$} & 40.2 & UDAp439 & 7.57 & 24.6 \\
\hline FIRM_13 & 4 & {$[30.8 ; 64.8]^{* * *}$} & 47.5 & S4_13001709 & 8.21 & 25.5 \\
\hline
\end{tabular}


Table 2 (continued)

\begin{tabular}{|c|c|c|c|c|c|c|}
\hline \multicolumn{7}{|l|}{ 'Bergeron' } \\
\hline Trait-Year & LG & QTL interval (IM) & Location & Nearest marker (MQM) & lod & $\% \operatorname{expl}$ \\
\hline FIRM_13 & 4 & {$[30.8 ; 64.8]^{* * *}$} & 47.9 & SSR4_13182815 & 7.92 & 24.5 \\
\hline SS_13 & 4 & {$[37.9 ; 52.9]^{* * *}$} & 38.8 & S4_10035210 & 8.45 & 26.7 \\
\hline SS_13 & 4 & {$[37.9 ; 52.9]^{* * *}$} & 40.2 & UDAp439 & 8.38 & 26.7 \\
\hline MALIC_13 & 8 & {$[0.0 ; 3.1]^{* *}$} & 0.0 & S8_4773161 & 4.1 & 59.4 \\
\hline \multicolumn{7}{|c|}{ 'Currot' (from the GxC Map) } \\
\hline CAL_12 & 3 & {$[0.0 ; 2.5]^{* *}$} & 0.0 & S3_899478 & 4.56 & 29.6 \\
\hline SKC_12 & 3 & {$[42.5 ; 84.4]^{* * *}$} & 67.6 & S3_19398598 & 22.84 & 52.0 \\
\hline FLSC_12 & 3 & {$[42.5 ; 84.4]^{* * *}$} & 67.6 & S3_19398598 & 18.93 & 44.5 \\
\hline FIRM_12 & 3 & {$[47.1 ; 65.2]^{* * *}$} & 52.8 & SSR3_15343739 & 7.86 & 20.9 \\
\hline FIRM_12 & 3 & {$[47.1 ; 65.2]^{* * *}$} & 53.0 & S3_15588939 & 8.17 & 21.2 \\
\hline SS_12 & 4 & {$[26.1 ; 64.1]^{* * *}$} & 46.2 & UDAp439 & 8.1 & 21.7 \\
\hline SW_13 & 2 & {$[21.1 ; 53.6]^{* * *}$} & 38.6 & S2_18992724 & 8.19 & 20.7 \\
\hline SKC_13 & 3 & {$[53.5 ; 84.4]^{* * *}$} & 67.6 & S3_19398598 & 21.25 & 47.3 \\
\hline FLSC_13 & 3 & {$[60.2 ; 84.4]^{* * *}$} & 67.6 & S3_19398598 & 15.52 & 37.3 \\
\hline FIRM_13 & 2 & {$[16.6 ; 38.6]^{* * *}$} & 21.1 & $\mathrm{~S} 2 \_12550486$ & 7.64 & 21.8 \\
\hline SS_13 & 4 & {$[31.1 ; 64.1]^{* * *}$} & 44.7 & S4_10035210 & 9.35 & 23.4 \\
\hline SS_13 & 4 & {$[31.1 ; 64.1]^{* * *}$} & 46.2 & UDAp439 & 10.85 & 27.3 \\
\hline MALIC_13 & 2 & {$[16.6 ; 48.6]^{* *}$} & 21.1 & $\mathrm{~S} 2 \_12550486$ & 7.17 & 20.7 \\
\hline MALIC_13 & 8 & {$[38.7 ; 44.8]^{* *}$} & 44.8 & S8_17732612 & 7.86 & 20.8 \\
\hline
\end{tabular}

discarded because of the high number of repetitions found in the apricot genome. RPL12 and CYP1 were used as reference genes for data normalisation (Niu et al. 2014), and the levels of relative expression were calculated by the $2^{-\Delta \Delta \mathrm{Ct}}$ method (Pfaffl 2001), taking the $\mathrm{Ct}$ value from the 'GC 2-11-A' sample as the reference expression level and using both housekeeping genes in the normalisation of gene expression (Vandesompele et al. 2002).

The spatial and temporal expression of structural genes in anthocyanin biosynthesis is determined by the combination and interaction between R2R3MYB, basic helix-loop-helix $(b H L H)$ and WD40type transcription factors (TFs), forming the MBW complex (Dare et al. 2008). Six MYB10-like and three bHLH-like TFs have been identified in peach. Of the six peach sequences potentially regulating anthocyanin biosynthesis, only three have been found to be expressed in apricot fruits: MYB10.1 (ppa026640m), MYB10.2 (ppa016711m), known PpMYB10 (Ravaglia et al. 2013) and MYB10.3 (ppa020385m). In the available peach genome sequence, the three MYB10s (MYB10.1, MYB10.2 and $M Y B 10.3$ ) are all located within $80 \mathrm{~kb}$ in LG3. In the current study, the maximum expression of these genes was found during flowering for all three genes. In the mesocarp, on the other hand, expression during ripening was only relevant for MYB10.1 and MYB10.3, which were detectable in the mesocarp and peel and were highest in the mesocarp around the stone. MYB10 showed higher expression in 'GC 211 ' than in 'GC 3-7', however (Fig. 3). The KruskalWallis rank sum test confirmed statistical differences between genotypes that decreased during the fruit ripening process in both of them although not significantly $\left(p\right.$ value $_{\text {state }}=0.1979$ and $p$ value $_{\text {genotype }}=$ 0.0004868),

At the beginning of LG5, a QTL for SKC was described close to S5_8566413 and AMPA105 in ' $G$ ' and ' $\mathrm{C}$ '. The ANS gene is located near this QTL (Supplementary Fig. 1 and Fig. 2; Supplementary Table 1). The analysis of differential expression by qPCR showed statistically significant differences between states and genotypes $\left(p\right.$ value $_{\text {state }}=0.03631$ and $p$ value genotype $=$ 

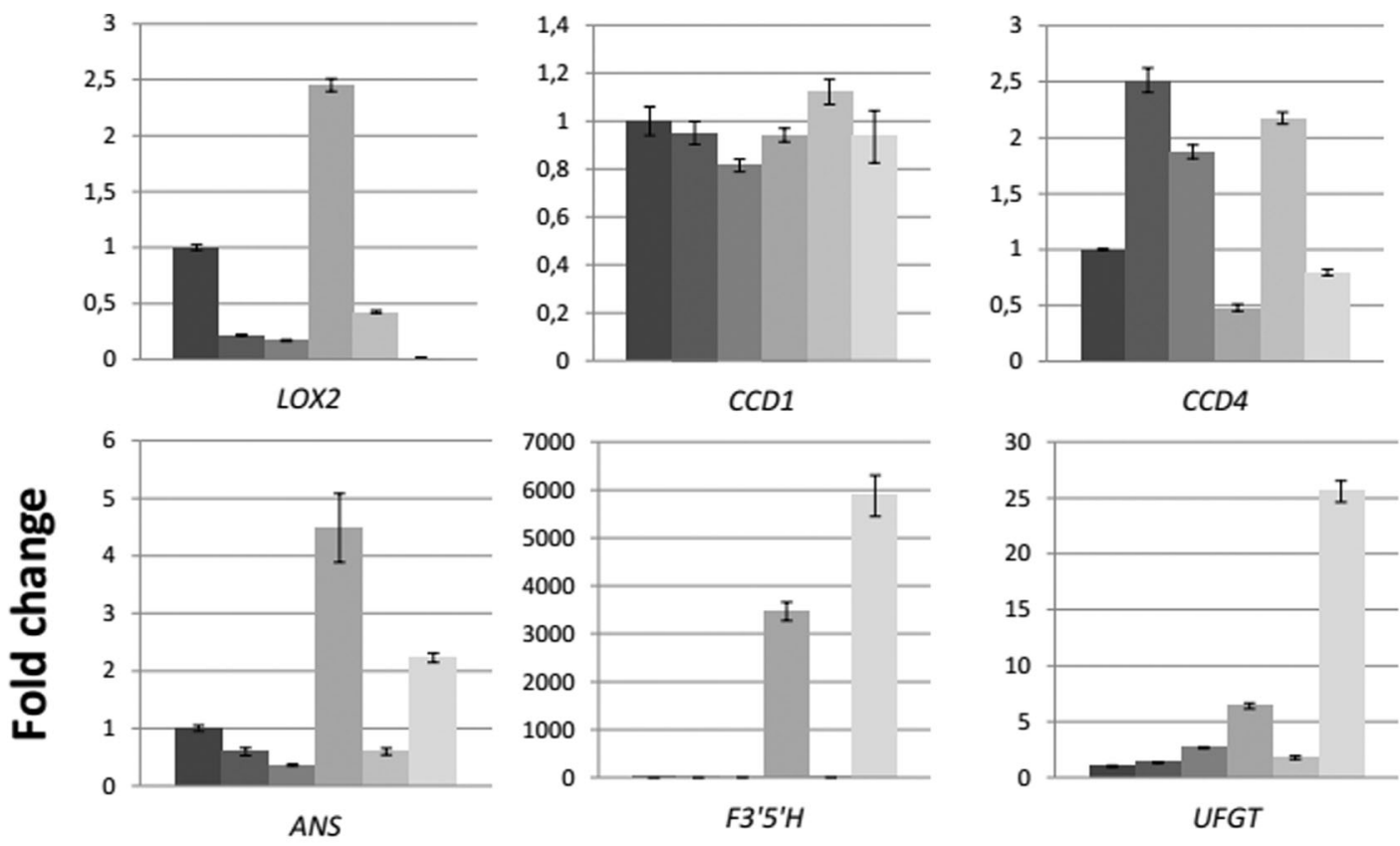

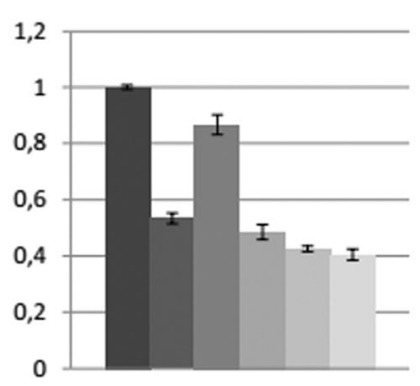

MYB 10

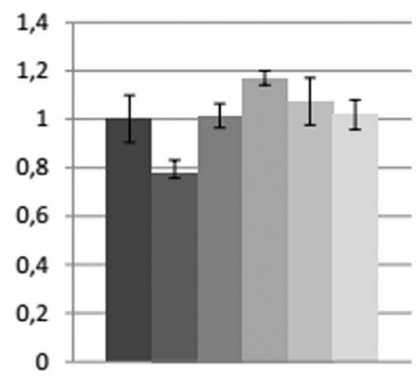

NAD ME
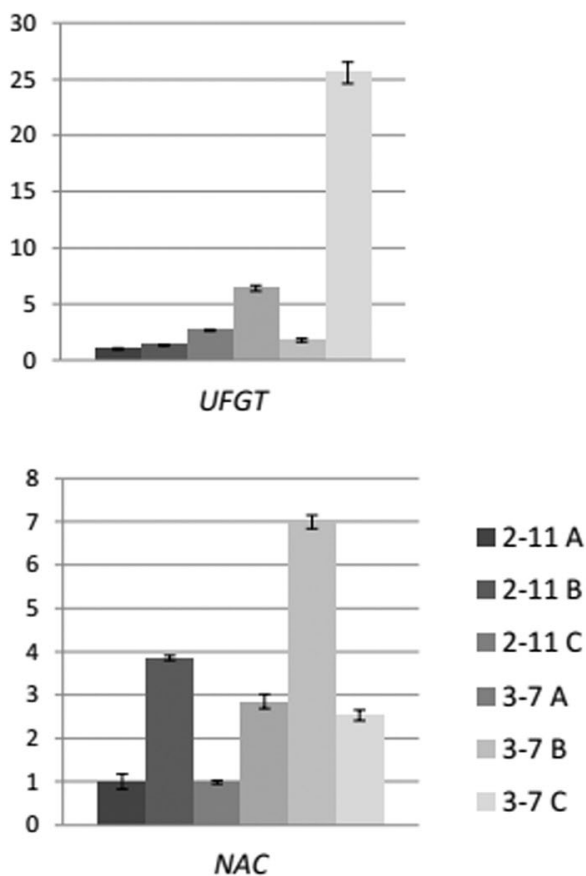

Fig. 3 Gene expression analysis using qPCR of candidate genes related to carotenoid biosynthesis (LOX 2, CAD 1, DXP 1, CCD1 and CCD4); anthocyanin biosynthesis (MYB 10, bHLH, DFR, F3'
5'H, UFGT and ANS), organic acid biosynthesis (NAD ME) and ripening date (NAC) linked to QTLs

between genotypes but not between ripening states ( $p$ value $_{\text {state }}=0.1678$ and $p$ value $_{\text {genotype }}=0.003892$ ). There was no minimal expression of $F 3^{\prime} 5^{\prime} H$ in the 'GC 2-11' genotype. In 'GC 3-7', on the other hand, the expression of $F 3$ ' 5 ' $H$ increased during the ripening process and reached its maximum expression in ripe fruit (Fig. 3).

The UFGT gene was located in the middle of LG6 in 'B', very close to the FLSC QTL (Supplementary Fig. 1 and Fig. 2; Supplementary Table 1). The expression of UFGT showed a sharp increase with a steep slope between veraison and maturity. The Kruskal-Wallis rank sum test confirmed statistically significant differences between genotypes and ripening states $\left(p\right.$ value $_{\text {state }}=$ 0.03631 and $p$ value $_{\text {genotype }}=0.005411$ ). Furthermore, 
the differences between genotypes were most significant in the expression of $U F G T$, which was upregulated in the 'GC 3-7' genotype during the entire fruit ripening process (Fig. 3).

The acidity trait is defined by the presence of a NADdependent malic enzyme (NAD-ME) close to LG2 QTL related to the malic acid in ' $G$ ' and ' $C$ ' (Supplementary Figs. 1 and 2; Supplementary Table 1). During the ripening process, the expression of $N A D-M E$ decreased in both apricot genotypes (Fig. 3). No statistically significant differences were found between states, but there were statistically significant differences between genotypes $\left(p\right.$ value $_{\text {state }}=0.1284$ and $p$ value genotype $=$ $0.0234)$. Furthermore, the decrease in NAD-ME correlated with the increase in malic acid during fruit ripening in both genotypes.

LOX 2 genes were found in the BLSC, MALIC, SS and FIRM QTL regions in LG2. The expression of $L O X$ 2 was highest at the beginning of the ripening process (Fig. 3) and decreased until the fruit was completely mature in both genotypes (Supplementary Figs. 1 and 2; Supplementary Table 1). Statistical analysis confirmed significant differences between ripening states but not between genotypes $\left(p\right.$ value $_{\text {state }}=0.0005111$ and $p$ value $_{\text {genotype }}=0.6911$ ).

In the regions linked to BSKC, FLSC and SKC in LG1 and LG2, two genes related to carotenoid synthesis, including carotenoid cleavage dioxygenase 1 $(C C D 1)$ and carotenoid cleavage dioxygenase 4 (CCD4), were identified (Supplementary Figs. 1 and 2; Supplementary Table 1). In our linkage map, $C C D 1$ was located at the beginning of LG1, in the middle of a FLSC QTL in ' $\mathrm{C}$ '. $C C D 1$ was located in LG2 inside the FLSC QTL in ' $C$ ', but the expression did not change during the ripening process or between genotypes $(p$ value $_{\text {state }}=0.2963$ and $p$ value $\left._{\text {genotype }}=0.05763\right)$. CCD4 was located in LG1, inside BLSC and FLSC in ' $\mathrm{B}$ ' in the same position described in peach (Adami et al. 2013). The expression of CCD4 was upregulated ( $p$ value $_{\text {state }}=0.002117$ and $p$ value genotype $=0.04694$ ) to a significantly greater extent in the 'GC 2-11' genotype than in 'GC 3-7', and the highest levels occurred during veraison (Fig. 3). These results correlated with the flesh colour of each genotype - either light yellow in 'GC 211 ' or orange in ' $\mathrm{GC} 3-7$ ' - at the end of the ripening process.

Finally, NAC was located inside the SS QTL in LG4 for all of the tested genotypes. Furthermore, it was upregulated more in 'GC 3-7' than in 'GC 2-11' during the ripening process (Fig. 3), which correlated with the MD of each genotype. The analysis of differential expression by qPCR showed statistically significant differences between states and genotypes ( $p$ value $_{\text {state }}=$ 0.002754 and $p$ value $_{\text {genotype }}=0.04694$ ), which correlated with the increase in SS during the ripening process in both genotypes and also with the early maturation date of 'GC 3-7' compared to that of 'GC 2-11'.

\section{Discussion}

Descriptive phenotypic analysis

The presence of transgressive trait values in the phenotype evaluation is probably due to the influence of the genetic background of the parents, which largely determines the segregation patterns obtained in the offspring (Salazar et al. 2013). In addition, the traits evaluated show the influence of genetic background and intermediate inheritance due to the transmission of co-dominant genes. We can thus confirm the polygenic nature and quantitative inheritance of the studied traits as well as the large variability of the seedlings in each population and the good correlation between years, as found by Salazar et al. (2013). Moreover, some correlations, such as acidity and fruit skin colour, could indicate that low skin colour $\left(\mathrm{H}^{\circ}\right)$ or a more reddish skin colour could be related to high acidity levels. Ruiz et al. (2008) obtained similar results. In addition, Ruiz et al. (2005b) linked the carotenoid content to titratable acidity, obtaining a Pearson correlation of around 0.40 . However, despite the fact that significant correlations have been identified between skin colour, acidity and carotenoid content, we can assert that these correlations were quite low.

Marker-trait analyses

\section{Morphological quantitative traits (stone and fruit weight and diameter)}

Some of our results agree with previous results from Quilot et al. (2004) and Eduardo et al. (2011), who located different QTLs for fruit weight in LGs 5 and 6, respectively. Eduardo et al. (2011) also linked the SSR marker UDP412 located in LG6 to fruit weight in the 'Contender' $\times$ 'Ambra' peach population. Campoy et al. (2015) placed a major QTL for fruit weight in LG5 of 
two cherry $F_{1}$ progeny and identified some candidate genes in the Prunus persica genome v1.0.

There are few studies to date about fruit diameter. In a different peach progeny, for instance, Abbott et al. (1998) detected QTLs in LG1 and LG8, and Cantín et al. (2010) in LG4. Wang et al. (2000) described QTLs related to fruit size in LG2 and LG6 in cherry. De Franceschi et al. (2013) identified 23 FW2.2/CNR (cell number regulator) genes involved in fruit size along the peach genome in all linkage groups. These authors located two of the CNR genes for cherry (PavCNR12 and PavCNR20) in the QTL interval of LGs 2 and 6. In our populations, we also observed important QTLs for these traits in the same LGs and in similar positions to the CNR genes described by De Franceschi et al. (2013).

Recently, Fresnedo-Ramírez et al. (2016) studied fruit diameter (FD) and fruit weight (FW) as the most important yield traits using a pedigree analysis under a Bayesian framework. These authors used a pedigree of 464 individuals from different founders, breeding lines, commercial varieties, phantom parents and progeny. They identified five QTLs explaining 29 and $17 \%$ of phenotypic variance for FD and FW, respectively. However, the most relevant QTLs were identified on LGs 6 and 7 for two consecutive years linked to FD and FW in agreement with our results in ' $\mathrm{B} \times \mathrm{C}$ ' progeny. These approaches could be interesting for studying the most relevant genetic components of fruit quality traits in any breeding programme (Fresnedo-Ramírez et al. 2016).

Morphological qualitative traits (skin, flesh and blush colour)

As we have seen, the QTLs for these traits are located in several linkage groups, which indicates the polygenic nature of the traits. This trend has also been observed in other Prunus species. In peach, for example, QTLs for skin colour have been located in LG2 (Quarta et al. 2000); in LGs 2 and 6 (Verde et al. 2002); in LG5 (Quilot et al. 2004); in LGs 3, 4, 6 and 7 (Eduardo et al. 2011); and in LG5 (Illa et al. 2011). In cherry, two QTLs were located in LGs 3 and 6 (Sooriyapathirana et al. 2010). Similarly, several authors have localised flesh colour QTLs in LG1 (Bliss et al. 2002; Martínez-García et al. 2013), LGs 1 and 3 (Quilot et al. 2004) and LG3 (Abbott et al. 1998; Illa et al. 2011) in peach as well as in LGs 3 and 8 (Sooriyapathirana et al. 2010) in cherry. In apricot progeny, Socquest-Juglard et al. (2012) located QTLs for fruit skin colour in LG3, and Ruiz et al. (2010) located skin colour QTLs at the end of the same LG in the 'Goldrich' $\times$ 'Moniquí' population, coinciding with 'Goldrich' in our population. Other authors such as Quilot et al. (2004) and Martínez-García et al. (2013) have located QTLs associated with red and yellow flesh on LG1.

Other studies in apricot have shown QTLs for flesh colour in LGs 1 and 6 (Salazar et al. 2013). Concerning candidate gene identification, a PavMYB10 gene [homologous to MdMYB10 in apple and to AtPAP1 in Arabidopsis (Espley et al. 2007)] was found at the end of LG 3, where the major QTL region for cherry skin and flesh colour is located. This suggests that this gene may be one of the main determinants of skin and flesh colour in cherry (Sooriyapathirana et al. 2010). For apple, the MdMYB10 transcription factor is involved in anthocyanin accumulation and is responsible for red skin and flesh colour (Espley et al. 2007; Chagné et al. 2007; Takos et al. 2006; Ban et al. 2007). These transcription factors in apple have been located in LG9, which is collinear with LG3 in peach (Illa et al. 2011). In our study, we identified the presence of an MYB gene located in the same QTL region as in cherry, close to S3_18629805 (Fig. 3). These data confirm synteny among the species belonging to the Rosaceae family.

\section{Organoleptic traits}

To date, few authors have referenced firmness QTLs. We would like to highlight those published in peach by Cantín et al. (2010) and Ogundiwin et al. (2009) in LGs $1,4,5,7$ and 8, as well as the major QTLs detected by Campoy et al. (2015) in LG6 in cherry progeny. The presence of several QTLs along different LGs undoubtedly indicates the polygenic nature of this trait and of the majority of fruit quality traits in general.

Regarding soluble solid content, many authors have described QTLs for single sugars like sucrose, fructose and glucose distributed throughout the peach LGs (Abbott et al. 1998; Dirlewanger et al. 1999; Quarta et al. 2000; Verde et al. 2002; Etienne et al. 2002a; Quilot et al. 2004; Cantín et al. 2010; Illa et al. 2011; Eduardo et al. 2011). In other species such as cherry, Wang et al. (2000) detected different QTLs in LGs 6 and 7, while in apricot, Ruiz et al. (2010) placed different QTLs in LGs 3 and 4 in agreement with Salazar et al. (2013), who identified QTLs in LGs 3, 4 and 5. In addition, in our progeny, the soluble solid content seems to be linked to ripening time and the fruit development 
period, because all of these traits are mainly influenced by linkage group 4 in the same genomic region (Dirlewanger et al. 2012; Salazar et al. 2013; Pirona et al. 2013).

Similarly, several authors have detected acidity QTLs in almost all peach LGs (Dirlewanger et al. 1999; Etienne et al. 2002a; Quilot et al. 2004; Cantín et al. 2010; Eduardo et al. 2011). In apricot, Ruiz et al. (2010) and Salazar et al. (2013) located acidity QTLs in LGs 6, 7, 8 and LGs 1, 2 and 4, respectively. As we have seen, it is difficult to find a specific region related to fruit acidity, and it would be necessary to saturate these QTL regions to define more specific loci linked to this trait. In apricot, LG2 in 'Goldrich' and LG8 in 'Currot' seem to be the most important LGs involved in acidity levels.

Finally, in our QTL analysis, the most relevant results are linked to fruit skin colour in LG3, soluble solid content in LG4 and acidity content in LGs 2 and 8. This allows us to establish a frame of reference in the search for major genes linked to fruit quality traits in apricot using molecular markers. We have to consider, however, that the most consistent and significant QTLs for skin colour and soluble solid content were identified in LGs 3 and 4, respectively (Fig. 3). In addition, new markers mapped in LG4 could be linked to the ripening time QTL previously reported by Salazar et al. (2016), where SSR4_13182815 is related to soluble solid content, reaching a PEV value of over 10, which could be used as a potential molecular marker for MAS (Table 2).

These molecular tools could be used for aligning specific regions of different species and for developing markers to be used for breeding purposes. Fruit skin colour offers a good example: this trait seems to be controlled by a specific region (and probably by the same gene) in the species belonging to the Rosaceae family. This has been reported in peach (Frett et al. 2014), apricot (Ruiz et al. 2010; Socquest-Juglard et al. 2012), cherry (Sooriyapathirana et al. 2010), plum (Salazar et al. 2017), apple (Espley et al. 2007; Chagné et al. 2007) and pear (Pierantoni et al. 2010).

Candidate genes and biological validation

Gene expression using qPCR showed variable expression patterns throughout the fruit development period with a relationship between validated candidate genes and fruit quality traits linked to QTLs (Supplementary Fig. 1 and Fig. 2; Supplementary Table 1). The qPCR results also showed the clear implication of the assayed genes in the ripening process, and there was a clear correlation between DNA and RNA results. We observed differential expression of ANS, CCD4, UFGT, F3'5' $H, N A D-M E$ and NAC genes between the two assayed genotypes. In addition, we observed clear expression differences during the ripening process in $N A C$, $A N S, U F G T, C C D 4$ and LOX 2. ANS, UFGT and $F 3^{\prime} 5$ ' $H$ and $L O X 2$ were upregulated in the 'GC 3-7' genotype and were responsible for the flesh, skin and blush colour; NAC was also upregulated in the 'GC 3-7' genotype and was responsible for maturity date. In ' $\mathrm{GC}$ 2-11', CCD4 and MYB10 were upregulated and were responsible for flesh, skin and blush colour. $N A D-M E$, on the other hand, was upregulated in 'GC 3-7', decreased during the ripening process and was responsible for the acidity content.

The transcription factor MYB10 was upregulated in 'GC 2-11' in fruits with yellow flesh and skin and decreased during the fruit ripening period. We speculate that the anthocyanin biosynthetic pathway may be controlled by transcriptional complexes in apricot, and the transcriptional complexes are probably the orthologs of MYB regulators that can induce the transcription of anthocyanin pathway genes (Zhou et al. 2012, 2015). In Japanese plum (P. salicina L.), TFs of the R2R3MYB subfamily of the MYB family were linked to the regulation of anthocyanin biosynthesis. Analysis shows that a sustained increase in the expression of PSMYB10 began in $\mathrm{S} 2$ in the skin of all the red cultivars and continued until S4. Furthermore, PSMYB10 showed the highest positive correlation with anthocyanin accumulation and ANS and UFGT gene expression, suggesting a putative function of $P S M Y B 10$ in the regulation of transcriptional control during anthocyanin biosynthesis. On the other hand, there is a significant negative correlation between anthocyanin accumulation, ANS and UFGT gene expression and the highest expression of PSMYB1 in all yellow tissues (Gonzalez et al. 2016). In addition, epigenetic mechanisms such as promoter methylation of $R 2 R 3 M Y B$ genes have been shown to play an important role in the regulation of anthocyanin accumulation in of apple (Telias et al. 2011) and pear fruits (Wang et al. 2013). Therefore, orthologs $R 2 R 3$ $M Y B$ and epigenetic modification must be thoroughly researched in order to deeply understand the anthocyanin biosynthetic pathway in apricot.

In apricot fruit, the un-blushed skin colour, green at the beginning, became red in conjunction with chlorophyll degradation and anthocyanin accumulation, which 
seems to occur early in fruit development and maturation. As the apricots ripened, the anthocyanin concentration increased in the skin, reaching a maximum and then decreasing toward the end of the maturation phase (Bureau et al. 2009).

The apricot species presents large variability in fruit colour, ranging from white ('Moniqui') and orange ('Goldrich') to fruits largely covered with a strong red blush ('Orange Red'). Anthocyanins are the most important pigments responsible for red coloration in apricots. The anthocyanin biosynthetic pathway is a major branch of flavonoid metabolism. Flavonoid biosynthesis genes like ANS, F3' 5' $H$ and UFGT are highly conserved among species and are organised in several branches, leading to the production of different flavonoids. Some branches are species-specific, whereas others are almost ubiquitous. The major anthocyanin compounds found in apricot fruit skin are cyanidin-3-O-rutinoside followed by cyanidin-3-O-glucoside and peonidin-3-O-rutinoside (Bureau et al. 2009; Gouble et al. 2005; Jo et al. 2015; Ruiz et al. 2005a; Ruiz et al. 2005b; Ruiz et al. 2008; Ayour et al. 2016; Campbell et al. 2013; Ruiz and Egea 2008; Gomez and Ledbetter 1997; Marty et al. 2005).

$\mathrm{F} 3{ }^{\prime} \mathrm{H}$ and $\mathrm{F}^{\prime}{ }^{\prime}{ }^{\prime} \mathrm{H}$ determine the hydroxylation pattern of the B-ring of flavonoids and anthocyanins, which are necessary for leucocyanindin and leucodelphinidin production, respectively. These are the key enzymes that determine the anthocyanin structures and therefore colour (Gonzalez et al. 2016; Tanaka et al. 2008).

During fruit development, apricot undergoes a continuous accumulation of organic acids, which are used as respiratory substrates (Etienne et al. 2002b). All organic acids, including oxalate, tartrate, quinate, malate, citrate, fumarate and total organic acids, mostly increased during the early state of fruit development and decreased until fruits were fully ripe. Quinate, malate and citrate are the predominant organic acids throughout the whole fruit development and ripening period. As for the ratio of whole organic acids, malate is the first major organic acid in apricot, and the ratio of malate in the fruit decreased during development. Malate synthase $(M S)$ is the key enzyme for the synthesis of malic acid. Malic enzymes (malate oxidoreductases) catalyse the oxidative decarboxylation of malate to produce pyruvate. In apricot, malate could be metabolised by the NADP-malic enzyme (NADP-ME) and the NADmalic enzyme (NAD-ME). The decrease in $M S$ and increase in $N A D P-M E$ and $N A D-M E$ were together responsible for the malate decrease throughout the development and ripening process, which further confirms the correlation between the activity of these enzymes and malate accumulation (Xi et al. 2016).

In plants, lipoxygenase $(L O X)$ is closely related to fruit ripening and senescence. Additionally, fruit quality traits like fruit firmness, ethylene production and soluble solid content have been found to be affected by the differential expression of $L O X$ under different storage conditions (Guo et al. 2017). In the fatty acid pathway, unsaturated fatty acids linoleic acid (18:2) and linolenic acid (18:3) can be converted into hydroperoxides by $L O X$, which is consistent with the corresponding aroma products of the metabolic flux (Xi et al. 2016). PpaLOX2.2 has been identified in peach and may be required for fruit ripening during storage (Guo et al. 2017). Furthermore, LOX 2 was determined as a putative candidate gene for transforming aldehyde from fatty acids by $\beta$-oxidation, yielding the precursors for the terpene pathway, which is related to carotenoid content (Eduardo et al. 2012).

In the edible portion of apricot, $\beta$-carotene is the main pigment followed by $\beta$-cryptoxanthin and $\gamma$ carotene (Ruiz et al. 2005b). The mechanism that controls carotenoid accumulation is largely unknown. Recently, two different regulatory mechanisms have been postulated. One is focused on carotenoid degradation, and the other is focused on sink capacity. Carotenoids can be cleaved into volatile apocarotenoids in fruit by $C C D$, generating flavour compounds (Tanaka et al. 2008). The differential expression of CCD4 has thus been proposed as being the major determinant in the accumulation of carotenoids in peach fruit flesh (Brandi et al. 2011). In apricot, a rapid, significant increase in $C C D$ activity has been found during the fruit development process in both the peel and pulp (Zhang et al. 2010; Xi et al. 2016). CCD4 is the gene controlling flesh colour in peach, and its expression results in the degradation of carotenoids in white-fleshed genotypes, while the yellow colour arises as a consequence of its inactivation when the yellow phenotype originating from at least three independent mutations disrupts $C C D 4$ function, thus preventing carotenoid degradation (Adami et al. 2013). NAC is one of the largest plant transcription factor families and is a key regulator of developmental programs and stress response. NAC has been linked to maturity date (MD), where a few QTLs were detected with a higher explained variation. Fine mapping of the MD locus in peach identified the candidate gene (ppa008301m) encoding a transcription factor of the 
$N A C$ family as a possible causal gene (Pirona et al. 2013).

In our linkage map, there is a major QTL for SS where $N A C$ is located. As we have mentioned, this is related to the soluble solid content and seems to be linked to ripening time and the fruit development period, because all of these traits are mainly influenced by the same region in LG4 (Supplementary Fig. 1 and Fig. 2). This is likely due to a major pleoitropic effect of MD masking the identification of other QTLs for different traits (Dirlewanger et al. 2012; Salazar et al. 2013; Pirona et al. 2013; Balogh et al. 2018). In this case, with a longer ripening process, fruit quality traits have more time to develop and fruits have more time to accumulate sugars and acids (Eduardo et al. 2010). A sequence variant in a $N A C$ candidate gene with a 9 bp insertion (compared with the Prunus persica v1.0. reference genome) was shown to co-segregate with the MD trait and can be used in selecting early-maturity genotypes. The marker development on this sequence polymorphism provides a convenient molecular tool for discriminating between early- and late-ripening individuals in breeding populations (Pirona et al. 2013). The MD trait could thus be tentatively regarded as a co-dominant marker. These data indicate that MD could be controlled by the same locus within the Prunus species and suggest that selection for this trait should be efficient and rapidly integrated into breeding programmes (Dirlewanger et al. 2012).

\section{Conclusions}

Several QTLs related to fruit quality traits - such as fruit weight and stone weight, skin and flesh colour, firmness, soluble solid content and acidity-were identified in both ' $\mathrm{B} \times \mathrm{C}$ ' and $\mathrm{G} \times \mathrm{C}$ ' populations. The most significant QTLs for soluble solid content were localised in LG4 and for skin and flesh colour in LG3. We can highlight the presence of candidate genes for the soluble solid QTL in LG4 that are involved in diglucose and D-mannose binding (ppa001122m, ppa000854m and ppb001660m). Concerning skin colour, a gene encoding for an MYB transcription factor (previously linked to skin colour by other authors) was identified in the QTL region in LG3. The markers located in these QTL regions could be used for marker-assisted selection for all of the abovementioned $\downarrow$ traits. All of the genes linked to colour, acidity or ripening date located in these QTLs had an expression level in agreement with the observed phenotype in the apricot fruits. The potentially easiest traits for marker assisted selection are those related to Mendelian inheritance, such as skin colour, which has been reported in LG3 of peach, apricot and plum, and ripening time, which has been reported in LG4 in the same species. Results also show the clear implication of the assayed genes in the ripening process: the qPCR data confirm the QTL analyses, and the correlation is clear between the results collected on DNA and those observed with the RNA approach. The MYB10 gene is the best candidate gene for skin colour and was validated using qPCR expression. In addition, monitoring NAC expression is a good RNA marker for evaluating ripening progression. These results are of great interest for gene function validation and molecular breeding in apricot together with the development of PCR markers linked to skin colour for breeding programmes and the development of RNA markers for monitoring apricot fruit ripening.

Author contributions LD, PM-G and D.R. participated in the design and coordination of the study. D.R. and J.A.S. performed the phenotypic evaluation. B.E.G-G and J.A.S. Salazar carried out the SSR and SNP analyses, and B.E.G-G carried out the qPCR analysis. B.E.G-G, J.A.S., LD, PM-G and D.R. participated in the manuscript elaboration and discussion.

Funding information This study was financially assisted by the Seneca Foundation of the Region of Murcia (Saavedra Fajardo Postdoctoral fellow 20397/SF/17) during the stay of Juan A. Salazar in Murcia. This study was also supported by the "Apricot breeding" project of the Spanish Ministry of Economy and Competiveness (AGL2013-41452-R) and the project "Breeding stone fruit species assisted by molecular tools" of the Seneca Foundation of the Region of Murcia (19879/GERM/15).

Publisher's note Springer Nature remains neutral with regard to jurisdictional claims in published maps and institutional affiliations.

\section{References}

Abbott AG, Rajapakse S, Sosinski B, Lu ZX, Sossey-Alaoui K, Gannavarapu M, Reighard G, Ballard RE, Baird WV, Callahan A (1998) Construction of saturated linkage maps of peach crosses segregating for characters controlling fruit quality, tree architecture and pest resistance. Acta Hort 465: $41-49$

Adami M. De Franceschi P, Brandi F, Liverani A, Giovannini A, Rosati C, Dondini L, Tartarini S (2013) Identifying a carotenoid cleavage dioxygenase (ccd4) gene controlling yellow/ 
white fruit flesh color of peach. Plant Mol Biol Reporter 31 (5):1166-1175

Ayour J, Sagar M, Alfeddy MN, Taourirte M, Benichou M (2016) Evolution of pigments and their relationship with skin color based on ripening in fruits of different Moroccan genotypes of apricots (Prunus armeniaca L.). Scientia Hort 207:168175

Balogh E, Halász J, Szani Z, Hegedus A (2018) Correspondence between maturity date and molecular variations in a NAC transcription factor of diploid and polyploid Prunus species. Turkish J Agric Forest 42:136-144

Ban Y, Honda C, Hatsuyama Y, Igarashi M, Bessho H, Moriguchi T (2007) Isolation and functional analysis of a MYB transcription factor gene that is a key regulator for the development of red coloration in apple skin. Plant Cell Physiol 48: 958-970

Bazzano LA, He J, Ogden LG, Loria CM, Vupputuri S, Myers L, Whelton PK (2002) Fruit and vegetable intake and risk of cardiovascular disease in US adults the first national health and nutrition examination survey epidemiologic follow-up study. Am J Clin Nutr 76:93-99

Bliss FA, Arulsekar S, Foolad MR, Becerra V, Gillen AM, Warburton ML, Dandekar AM, Kocsisne GM, Mydin KK (2002) An expanded genetic linkage map of Prunus based on an interspecific cross between almond and peach. Genome 45:520-529

Brandi F, Bar E, Mourgues F, Horváth G, Turcsi E, Giuliano G, Rosati C (2011) Study of "Redhaven" peach and its whitefleshed mutant suggests a key role of CCD4 carotenoid dioxygenase in carotenoid and norisoprenoid volatile metabolism. BMC Plant Biol 11(1):24

Brown GS, Walker TD (1990) Indicators of maturity in apricots using biplot multivariate analysis. J Sci Food Agri 53:321331

Bureau S, Catherine M, Renard GC, Reich M, Ginies C, Audergon JM (2009) Change in anthocyanin concentrations in red apricot fruits during ripening. Food Sci Technol 42(1):372377

Campbell OE, Merwin IA, Padilla-Zakour OI (2013) Characterization and the effect of maturity at harvest on the phenolic and carotenoid content of Northeast USA apricot (Prunus armeniaca) varieties. J Agric Food Chem 61(51): 12700-12710

Campoy JA, Martínez-Gómez P, Ruiz D, Rees J, Celton JM (2010) Developing microsatellite multiplex and megaplex PCR systems for high throughput characterization of breeding progenies and linkage maps spanning the apricot genome. Plant Mol Biol Report 28:560-568

Campoy JA, Le Dantec L, Barreneche T, Dirlewanger E, QueroGarcía J (2015) New insights into fruit firmness and weight control in sweet cherry. Plant Mol Biol Report 33:783-796

Cantín CM, Crisosto CH, Ogundiwin EA, Gradziel T, Torrents J, Moreno MA, Gorgocena Y (2010) Chilling injury susceptibility in an intra-specific peach [Prunus persica (L.) Batsch]. Postharvest Biol Technol 58:79-87

Chagné D, Carlisle CM, Blond C, Volz RK, Whitworth CJ, Oraguzie NC, Crowhurst RN, Allan AC, Espley RV, Hellen RP, Gardiner SE (2007) Mapping a candidate gene (MdMYB10) for red flesh and foliage colour in apple. BMC Gen 8:212
Conesa A, Madrigal P, Tarazona S, Gomez-Cabrero D, Cervera A, McPherson A, Szcześniak MW, Gaffney DJ, Elo LL, Zhang X, Mortazavi A (2016) A survey of best practices for RNAseq data analysis. Genome Biol 17:13

Dare AP, Schaffer RJ, Lin-Wang K, Allan AC, Hellens RP (2008) Identification of a cis-regulatory element by transient analysis of co-ordinately regulated genes. Plant Meth 4:17

De Franceschi P, Stegmeir T, Cabrera A, van der Knaap E, Rosyara UR, Sebolt AM, Dondini L, Dirlewanger E, Quero-García J, Campoy JA, Iezzoni AF (2013) Cell number regulator genes in Prunus provide candidate genes for the control of fruit size in sweet and sour cherry. Mol Breed 32: 311-326

Dirlewanger E, Quero-García J, Le Dantec L, Lambert P, Ruiz D, Dondini L, Illa E, Quilot-Turion B, Audergon JM, Tartarini S, Letourmy P, Arùs P (2012) Comparison of the genetic determinism of two key phenological traits, flowering and maturity dates, in three Prunus species: peach, apricot and sweet cherry. Heredity 109(5):280-292

Dirlewanger E, Moing A, Rothan C, Svanella L, Pronier V, Guye A, Plomion C, Monet R (1999) Mapping QTLs controlling fruit quality in peach (Prunus persica (L.) Batsch). Theor Appl Genet 98:18-31

Doyle JJ, Doyle JL (1987) A rapid DNA isolation procedure for small quantities of fresh leaf tissue. Phytochem Bull 19:1115

Druka A, Potokina E, Luo Z, Jiang N, Chen X, Kearsy M, Waugh R (2010) Expression quantitative trait loci analysis in plants. Plant Biotech J 8:10-27

Eduardo I, Pacheco I, Chietera G, Bassi D, Pozzi C, Vecchietti A, Rossini L (2010) QTL analysis of fruit quality traits in two peach intraspecific populations and importance of maturity date pleiotropic effect. Tree Genet Gen 7(2):323-335

Eduardo I, Pacheco I, Chietera G, Bassi D, Pozzi C, Vecchietti A, Rossini L (2011) QTL analysis of fruit quality traits in two peach intraspecific populations and importance of maturity date pleiotropic effect. Tree Genet Gen 7:323-335

Eduardo I, Chietera G, Pirona R, Pacheco I, Troggio M, Banchi E, Bassi D, Rossini L, Vecchietti A, Pozzi C (2012) Genetic dissection of aroma volatile compounds from the essential oil of peach fruit: QTL analysis and identification of candidate genes using dense SNP maps. Tree Genet Gen 9(1):189-204

Espley RV, Hellens RP, Puterill J, Kutty-Amma S, Allan AC (2007) Red colouration in apple fruit is due to the activity of a MYB transcription factor, MdMYB10. Plant J 49:414 427

Etienne C, Rothan C, Moing A, Plomion C, Bodnes C, SvanellaDumas L, Cosson P, Pronier V, Monet R, Dirlewanger E (2002a) Candidate gene and QTLs for sugar and organic acid content in peach. Theor Appl Genet 105:145-159

Etienne C, Moing A, Dirlewanger E, Raymond P, Monet R, Rothan C (2002b) Isolation and characterization of six peach cDNAs encoding key proteins in organic acid metabolism and solute accumulation: involvement in regulating peach fruit acidity. Physiol Plantarum 114(2):259-270

Fresnedo-Ramírez J, Bink MC, van de Weg E, Famula TR, Crisosto CH, Frett TJ, Gradziel TM (2015) QTL mapping of pomological traits in peach and related species breeding germplasm. Mol Breed 35:1-19

Fresnedo-Ramírez J, Frett TJ, Sandefur PJ, Salgado-Rojas A, Clark JR, Gasic K, Peace CP, Anderson N, Hartmann TP, 
Byrne DH, Bink MCAM, van de Weg E, Crisosto CH, Gradziel TM (2016) QTL mapping and breeding value estimation through pedigree-based analysis of fruit size and weight in four diverse peach breeding programs. Tree Genet Gen 12:25

Frett TJ, Reighard GL, Okie WR, Gasic K (2014) Mapping quantitative trait loci associated with blush in peach [Prunus persica (L.) Batsch]. Tree Genet Gen 10:367-381

Gomez E, Ledbetter CA (1997) Development of volatile compounds during fruit maturation: characterization of apricot and plum x apricot hybrids. J Sci Food Agri 74(4):541-546

Gonzalez M, Salazar E, Cabrera S, Olea P, Carrasco B (2016) Analysis of anthocyanin biosynthesis genes expression profiles in contrasting cultivars of Japanese plum (Prunus salicina L.) during fruit development. Gene Expr Patterns 21(1):54-62

Guo S, Song Z, Ma R, Yang Y, Yu M (2017) Genome-wide identification and expression analysis of the lipoxygenase gene family during peach fruit ripening under different postharvest treatments. Acta Physiol Plantarum 39(5):111

Gouble B, Bureau S, Grotte M, Reich M, Reling P, Audergon JM (2005) Apricot postharvest ability in relation to ethylene production: influence of picking time and cultivar. In Proceedings of the 5th International Postharvest Symposium, Vols 1-3, edited by F. Mencarelli and P. Tonutti, 127-133. Leuven 1: International Society Horticultural Science

Hertog MGL, Hollman PCH, Katan MB, Kromhout D (1993) Estimation of daily intake of potentially anticarcinogenic flavonoids and their determinants in adults in the Netherlands. Nutr Cancer 20:21-29

Hollander, M., Wolfe, D. A., \& Chicken, E. (2013).Nonparametric statistical methods(Vol. 751). John Wiley \& Sons

Huang YF, Vialet S, Guiraud JL, Torregrosa L, Bertrand Y, Cheynier V, This P, Terrier N (2014) A negative MYB regulator of proanthocyanidin accumulation, identified through expression quantitative locus mapping in the grape berry. New Phytol 201(3):795-809

Illa I, Eduardo I, Audergon JM, Barale F, Dirlewanger E, Li X, Moing A, Lambert P, Le Dantec L, Gao Z, Poëssel JL, Pozzi C, Rossini L, Vecchietti A, Arús P, Howad W (2011) Saturating the Prunus (stone fruits) genome with candidate genes for fruit quality. Mol Breed 28:667-682

Infante R, Martínez-Gómez P, Predieri S (2008) Quality oriented fruit breeding: peach [Prunus persica (L.) Batsch]. J Food Agri Environ 6:342-356

Infante R, Martínez-Gómez P, Predieri S (2011) Breeding for fruit quality in Prunus. In: Jenks MA, Bebeli PJ (eds) Breeding for fruit quality. Ed. Wiley and Blackwel, New York (USA), pp 201-229

Jo Y, Lian S, Cho JK, Choi H, Chu H, Cho WK (2015) De novo transcriptome assembly of two different apricot cultivars. Gen Data 6:275-276

Lang L, Xu A, Ding J, Zhang Y, Zhao N, Tian ZS, Liu YP, Wang Y, Liu X, Liang FH (2017) Quantitative trait locus mapping of salt tolerance and identification of salt-tolerant genes in Brassica napus L. Front Plant Sci 8:100

Li H, Handsaker B, Wysoker A, Fennell T, Ruan J, Homer N, Durbin R (2009) The sequence alignment/map format and SAMtools. Bioinformatics 25(16):2078-2079
Machlin LJ (1995) Critical assessment of the epidemiological data concerning the impact of antioxidant nutrients on cancer and cardiovascular disease. Crit Rev Food Sci Nutr 35:41-50

Martínez-García PJ, Fresnedo-Ramírez J, Parfitt DE, Gradziel TM, Crisosto CH (2013) Effect prediction of identified SNPs linked to fruit quality and chilling injury in peach [Prunus persica (L.) Batsch]. Plant Mol Biol 81:175-188

Marty I, Bureau S, Sarkissian G, Gouble B, Audergon JM, Albagnac G (2005) Ethylene regulation of carotenoid accumulation and carotenogenic gene expression in colourcontrasted apricot varieties (Prunus armeniaca). J Exp Botany 56(417):1877-1886

Milne I, Stephen G, Bayer M, Cock PJ, Pritchard L et al (2013) Using tablet for visual exploration of second-generation sequencing data. Brief Bioinf 14:193-202

Niu J, Zhu B, Cai J, Li P, Wang L, Dai H, Qiu L, Yu H, Ha D, Zhao H, Zhang H, Lin S (2014) Selection of reference genes for gene expression studies in Siberian apricot (Prunus sibirica L.) germplasm using quantitative real-time PCR. PLoS One 9(8):e103900

Ogundiwin EA, Peace CP, Gradziel TM, Parfitt DE, Bliss FA, Crisosto CH (2009) A fruit quality gene map of Prunus. BMC Gen 10:587

Pierantoni L, Dondini L, De Franceschi P, Musacchi S, WinkelShirley BJ, Sansavini S (2010) Mapping of an anthocyaninregulating MYB transcription factor and its expression in red and green pear, Pyrus communis. Plant Physiol Bioch 48: $1020-1026$

Pirona R, Eduardo I, Pacheco I, Linge CD, Miculan M, Verde I, Tartarini S, Dondini L, Pea G, Bassi D, Rossini L (2013) Fine mapping and identification of a candidate gene for a major locus controlling maturity date in peach. BMC Plant Biol 13: 166

Pfaffl MW (2001) A new mathematical model for relative quantification in real-time RT-PCR. Nucleic Acids Res 29:e45

Quarta R, Dettori MT, Sartori A, Verde I (2000) Genetic linkage map and QTL analysis in peach. Acta Hort 521:233-241

Quilot B, Wu BH, Kervella J, Génard M, Foulongne M, Moreau K (2004) QTL analysis of quality traits in an advanced backcross between Prunus persica cultivars and the wild relative species $P$. davidiana. Theor Appl Genet 109:884-897

Ravaglia D, Espley RV, Henry-Kirk RA, Andreotti C, Ziosi V, Hellens RP, Costa G, Allan AC (2013) Transcriptional regulation of flavonoid biosynthesis in nectarine (Prunus persica) by a set of R2R3 MYB transcription factors. BMC Plant Biol 13(1):68

RStudio Team (2015). RStudio: integrated development for R. RStudio, Inc., Boston, MA URL http://www.rstudio.com/

Ruiz D, Egea J (2008) Phenotypic diversity and relationships of fruit quality traits in apricot (Prunus armeniaca L.) germplasm. Euphytica 163:143-158

Ruiz D, Egea J, Gil MI, Tomás-Barberan FA (2005a) Characterization and quantitation of phenolic compounds in new apricot (Prunus armeniaca L.) varieties. J Agric Food Chem 53:9544-9552

Ruiz D, Egea J, Tomás-Barberán FA, Gil MI (2005b) Carotenoids from new apricot (Prunus armeniaca L.) varieties and their relationship with flesh and skin color. J Agric Food Chem 53: 6368-6374

Ruiz D, Reich M, Bureau S, Renard C, Audergon JM (2008) Application of reflectance colorimeter measurements and 
infrared spectroscopy methods to rapid and nondestructive evaluation of carotenoids content in apricot (Prunus armeniaca L.). J Agric Food Chem 56(13):4916-4922

Ruiz D, Lambert P, Audergon JM, Dondini L, Tartarini S, Adami M, Gennari F, Cervellati C, De Franceschi P, Sansavini S, Bureau S, Gouble B, Reich M, Renard CMGC, Bassi D, Testolin R (2010) Identification of QTLs for fruit quality traits in apricot. Acta Hort 862:587-592

Salazar JA, Ruiz D, Egea J, Martínez-Gómez P (2013) Transmission of fruit quality traits in apricot (Prunus armeniaca L.) and analysis of linked quantitative trait loci (QTLs) using simple sequence repeat (SSR) markers. Plant Mol Biol Report 31:1506-1517

Salazar JA, Ruiz D, Campoy JA, Sánchez-Pérez R, Crisosto CH, Martínez-García PJ, Blenda A, Jung S, Main D, MartínezGómez P, Rubio M (2014) Quantitative trait loci (QTL) and Mendelian trait loci (MTL) analysis in Prunus: a breeding perspective and beyond. Plant Mol Biol Report 32:1-18

Salazar JA, Rubio M, Ruiz D, Tartarini S, Martínez-Gómez P, Dondini L (2015) SNP development for genetic diversity analysis in apricot. Tree Genet Gen 11:15

Salazar JA, Ruiz D, Campoy JA, Tartarini S, Dondini L, MartínezGómez P (2016) Inheritance of reproductive phenology traits and related QTL identification in apricot. Tree Genet Gen 12(4):71

Salazar JA, Pacheco I, Shinya P, Zapata P, Silva C, Ruiz D, Martínez-Gómez P, Infante R (2017) Genotyping by sequencing for SNP-based linkage analysis and identification of QTLs linked to fruit quality traits in Japanese plum (Prunus salicina Lindl.). Front Plant Sci 8:476

Simpson CG, Cullen DW, Hackett CA, Smith K, Hallett PD, McNicol J, Woodhead M, Graham J (2017) Mapping and expression of genes associated with raspberry fruit ripening and softening. Theor Appl Genet 130:557-572

Sims ET, Comin D (1963) Evaluation of objective maturity indices for Halehaven peaches. Proc Am Soc Hortic Sci 82:125-130

Socquest-Juglard D, Christen D, Devènes G, Gessler C, Duffy B, Patocchi A (2012) Mapping architectural, phenological, and fruit quality QTLs in apricot. Plant Mol Biol Report 31:387397

Sooriyapathirana SS, Khan A, Sebolt AM, Wang D, Bushakra JM, Wang KL, Allan AC, Gardiner SE, Chagné H, Iezzoni AF (2010) QTL analysis and candidate gene mapping for skin and flesh color in sweet cherry fruit (Prunus avium L.). Tree Genet Gen 6:821-832

Souty M, Audergon JM, Chambroy Y (1990) Abricot: les critères de qualite'. L'Arboriculture fruitière 430:16-24

Sugiyama A, Omura M, Shimoda T, Fuji H, Endo T, Shimizu T, Nesumi H, Nonaka K, Ikoma Y (2014) Expression quantitative trait loci analysis of carotenoid metabolism-related genes in Citrus. J Japan Soc Hort Sci 83:32-43

Takos AM, Jaffe FW, Jacob SR, Bogs J, Robinson SP, Walker AR (2006) Light-induced expression of a MYB gene regulates anthocyanin biosynthesis in red apples. Plant Physiol 142: 1216-1232
Tanaka Y, Sasaki N, Ohmiya A (2008) Biosynthesis of plant pigments: anthocyanins, betalains and carotenoids. Plant $\mathrm{J}$ 54(4):733-749

Telias A, Kui LW, Stevenson DE, Cooney JM, Hellens RP, Allan AC, Hoover EE, Bradeen JM (2011) Apple skin patterning is associated with differential expression of MYB10. BMC Plant Biol 11:14

Van den Berg H, Faulks R, Fernando Granado H, Hirschberg J, Olmedilla B, Sandmann G, Southon S, Stahl W (2000) The potential for the improvement of carotenoid levels in foods and the likely systemic effects. J Sci Food Agric 80:880-912

Van Ooijen JW (2006) JoinMap 4, software for the calculation of genetic linkage maps in experimental populations. Wageningen, Kyazma

Vandesompele J, De Preter K, Pattyn F, Poppe B, Van Roy N, De Paepe A, Speleman F (2002) Accurate normalization of realtime quantitative RT-PCR data by geometric averaging of multiple internal control genes." Gen Biol 3 (7): RESEARCH0034

Verde I, Quarta R, Cerdrola C, Dettori MT (2002) QTL analysis of agronomic traits in a $\mathrm{BC} 1$ peach population. Acta Hort 592: 291-297

Verde I, Abbott AG, Scalabrin S, Jung S, Shu S, Marroni F et al (2013) The high-quality draft genome of peach (Prunus persica) identifies unique patterns of genetic diversity, domestication and genome evolution. Nat Genet 45(5):487-494

Voorrips RE (2002) MapChart: software for the graphical presentation of linkage maps and QTLs. J Hered 93:77-78

Wang D, Karle R, Iezzoni AF (2000) QTL analysis of flower and fruit traits in sour cherry. Theor Appl Genet 100:535-544

Wang Z, Meng D, Wang A, Li T, Jiang S, Cong P, Li T (2013) The methylation of the PcMYB10 promoter is associated with green-skinned sport in Max Red Bartlett pear. Plant Physiol 162(2):885-896

Xi W, Zheng H, Zhang Q, Li W (2016) Profiling taste and aroma compound metabolism during apricot fruit development and ripening. Int J Mol Sci 17:998

Xie F, Xiao P, Chen D, Xu L, Zhang B (2012) miRDeepFinder: a miRNA analysis tool for deep sequencing of plant small RNAs. Plant Mol Biol 80(1):75-84

Ye J, Liu P, Zhu C, Qu J, Wang X, Sun Y, Sun F, Jiang Y, Yue G, Wang C (2014) Identification of candidate genes JcARF19 and JcIAA9 associated with seed size traits in Jatropha. Funct Integr Genomics 14(4):757-766

Zhang B, Shen JY, Wei WW, Xi WP, Xu CJ, Ferguson I, Chen KS (2010) Expression of genes associated with aroma formation derived from the fatty acid pathway during peach fruit ripening. J Agri Food Chem 58(10):6157-6165

Zhou Y, Guo D, Li J, Cheng J, Zhou H, Gu C, Gardiner S, Han YP (2012) Coordinated regulation of anthocyanin biosynthesis through photorespiration and temperature in peach (Prunus persica). Tree Genet Gen 9(1):265-278

Zhou H, Lin-Wang K, Wang H, Gu C, Dare AP, Espley RV, He H, Allan AC, Han Y (2015) Molecular genetics of blood-fleshed peach reveals activation of anthocyanin biosynthesis by NAC transcription factors. Plant J 82(1):105-121 